\title{
A Microstructure Study of Circuit Breakers in the Chinese Stock Markets
}

\author{
By
}

Steven Shuye Wang

Renmin University

Kuan Xu

Dalhousie University

Hao Zhang

University of Victoria

Working Paper No. 2019-02

July 222019

\section{DEPARTMENT OF ECONOMICS}

DALHOUSIE UNIVERSITY

6214 University Avenue

PO Box 15000

Halifax, Nova Scotia, CANADA

B3H 4R2 


\title{
A Microstructure Study of Circuit Breakers in the Chinese Stock Markets
}

\author{
Steven Shuye Wang \\ Kuan $\mathrm{Xu}^{*}$ \\ Hao Zhang
}

\footnotetext{
${ }^{*}$ Corresponding Author: Kuan Xu, Department of Economics, Dalhousie University, PO Box 15000, Halifax, NS, Canada B3H 4R2, Email: kuan.xu@dal.ca, Tel: +1 9024946995 \& Department of Economics, Sobey School of Business, Saint Mary's University, 923 Robie Street, Halifax, NS, Canada B3H 3C3. Steven Shuye Wang, School of Business, Renmin University of China, 59 Zhongguancun St., Beijing, 100872 E-mail: wangshuye@ruc.edu.cn. Hao Zhang, Peter B. Gustavson School of Business, University of Victoria, PO Box 1700 STN CSC, Victoria, BC, Canada V8W 2Y2 Email: hzhang@uvic.ca. Steven S. Wang acknowledges the financial support from the National Natural Science Foundation of China (Project No. 71572191). Kuan $\mathrm{Xu}$ thank University of Toronto and Renmin University of China for providing visiting opportunities during the Winter and Summer of 2018. Hao Zhang acknowledges the financial support of a Gustavson Executive Programs Research Grant. We thank the participants at the 25th Multinational Finance Society Conference, the 4th Frontiers of Business Research in China International Symposium, and the 9th International Conference of the Financial Engineering and Banking Society (FEBS) for their helpful comments. We also thank Dr. Mark Liu, the Special Issue Managing Guest Editor of the Pacific Basin Finance Journal, and two anonymous referees for constructive comments and suggestions. All remaining errors are the authors' responsibilities.
} 


\title{
A Microstructure Study of Circuit Breakers in the Chinese Stock Markets
}

\begin{abstract}
Based on rare policy changes in the Chinese stock market in January 2016, we study the impacts of market-wide circuit breakers on market microstructure. To test if market-wide circuit breakers have the "cooling effect" and the magnet effect, we use high frequency transactions and limit order book data and Lasso IV models for endogenous market microstructure variables and exogenous policy variables based on a novel identification strategy. We find that market-wide circuit breakers have no "cooling effect" in decelerating falling prices (or returns) or reducing market volatility and order imbalance. Their presence does not affect bid-ask spreads but does reduces the large-, mid-, and small-sized trades in volume and trades. We also find that marketwide circuit breakers indeed induce significant magnet effects on stock returns, order imbalance, quote imbalance, and trades of various sizes.
\end{abstract}

JEL Codes: G10, G15

Keywords: circuit breakers; stock return; market volatility; order imbalance; trading activities; liquidity; spreads; quote imbalances; size of trades; magnet effect; China Theme Keywords: circuit breakers 


\section{Introduction}

Circuit breakers are widely adopted adopted by the financial regulators around the world to ensure investor protection and to increase market integrity and stability (Gomber et al., 2016). The proportion of the exchanges using circuit breakers among all surveyed by WFE increased from 60\% in 2008 (WFE, 2008) to 86\% in 2016 (WFE, 2016).

In the finance literature, among three categories of circuit breakers in stock markets, price limits ${ }^{1}$ and firm-specific trading halt: ${ }^{2}$ have been well researched, but the study on market-wide circuit breakers is limited and inconclusive because it is rare to witness a sharp fall of the stock market that triggers market-wide circuit breakers. In contrast to singlestock price limits which allow trading at the limit price, market-wide circuit breakers, once triggered, result in trading halts for all stocks on an exchange or market closure. Therefore, the impacts of market-wide circuit breakers on market microstructure are of interest to both researchers and policy makers. The unique experience in the Chinese stock market during January 2016 provides a valuable opportunity for investigating the impacts of market-wide circuit breakers.

This paper makes three contributions to the literature. First, we examine the "cooling effect" of market-wide circuit breakers on stock return (or prices) and market volatility using high-frequency intraday data. We also examine order imbalance, trading activities in volume and trades, liquidity, and sizes of trades. The impacts of market-wide circuit breakers on these microstructure variables have not been examined in previous research. This paper aims to fill the gap in the literature. Second, we investigate the so-called magnet effect, which refers to the situation where prices fall much sooner to circuit breakers' thresholds because of their very existence. The magnet effect could be more pervasive in worsening, rather than improving, the market equilibrium. To the best of our knowledge, this is one of the first few studies on the magnet effect with both market-wide circuit breakers and individual stock price limits implemented jointly, as is the case in China during January 2016. We also present evidence of the magnet effect when circuit breakers are imposed while controlling for the effect of pseudo circuit breakers when circuit breakers are not actually imposed (Lee, Ready, and Sequin, 1994). Third, we pay a special attention to the interconnections

\footnotetext{
${ }^{1}$ Price limits restrict the price movements within and at the limits set for individual securities' trading. This is the case for China.

${ }^{2}$ Firm-specific trading halts represent a temporary suspension of trading for a particular security when anticipating a critical news announcement, or correcting an order imbalance, or being imposed by regulatory bodies.
} 
among, and therefore the endogeneity of, market microstructure variables observed in the high frequency intraday data and how circuit breakers affect stock returns, market volatility, order imbalance, trading activities in volume and trades, liquidity, and sizes of trades.

The existing theoretical studies suggest that circuit breakers cause the "cooling effect". That is, they allow investors to have more time to digest, and react to, new information, reduce order imbalance, and improve liquidity so that they mitigate market panic. Grossman and Miller (1988) show that the high demand for intermediacy causes crashes while delayed opening for trading could alleviate order imbalance. While trading halts induced by the market-wide circuit breakers are thought to reduce order imbalance and improve liquidity, there is no consensus whether circuit breakers lower or raise price volatility. On the one hand, Greenwald and Stein (1991) illustrate theoretically that circuit breakers may help to deal with the lack of liquidity and higher price volatility. On the other hand, Chen, Petkuhov, and Wang (2017) show theoretically that in a falling market, circuit breakers cause prices to fall and cause realized volatility and conditional volatility to rise.

The empirical evidence on the impacts of circuit breakers on volatility and liquidity, however, is quite mixed. For the U.S. market, Kuhn, Kuserk and Locke (1991) study cash and stock index futures markets on October 13th and 16th, 1989, when trading was suspended for several New York Stock Exchange (NYSE) stocks, and find that circuit breakers do not reduce price volatility. Lee, Ready, and Seguin (1994) investigate the effect of firmspecific NYSE trading halts on volume and price volatility, and find that trading halts increase, rather than decrease, both volume and volatility. Gerety and Mulherin (1992) find that circuit breakers do not necessarily calm down the market because the volume at the NYSE's closing is positively related to the expected price volatility overnight and the opening volume is positively related to both expected and unexpected volatility from the previous night. Corwin and Lipson (2000) investigate order flow and liquidity changes before, during, and after the NYSE's trading halts between 1995 and 1996 and find that although trading halts allow investors to cancel and adjust their orders around new prices, they do not reduce volatility and do not induce investors to provide more liquidity. Similarly, Goldstein and Kavajecz (2004) examine the trading activities on October 27th, 1997, when market-wide circuit breakers were triggered on the NYSE, and find that the reduction in liquidity occurred not on the day when circuit breakers were triggered, but on the following day, because traders were unwilling to resubmit their expired orders from the previous day. For non-US markets, Lauterbach and Ben-Zion (1993) examine the order flow data from the Tel-Aviv Stock Exchange during the crash of October 1987 and find that trading halts and 
price limits reduce the next-day open order imbalance and the initial price fluctuations and losses, but no effect on the long-run response. Kim and Rhee (1997) examine the Tokyo Stock Exchange price limit system and find that price limits are ineffective in reducing price volatility. Wong, Chang and $\mathrm{Tu}$ (2009) analyze the data of the Taiwan Stock Exchange (TWSE) and find that when price limit halts are imminent, trading activities intensify with higher volatility.

The existing theoretical studies also suggest that circuit breakers cause the so-called magnet effect, rather than the "cooling effect". Subrahmanyam (1994) shows theoretically that, with the presence of circuit breakers, when the price falls and approaches the limit, strategic traders would divide large trading orders and advance their smaller trades in time or submit large orders sub-optimally in a concentrated fashion to ensure their ability to trade, rather than holding back their trades. Hence, such trading activities are more likely to lead severe price drops to trigger circuit breakers sooner. This perverse consequence induced by circuit breakers is called the magnet effect. It can also increase price variability, market liquidity, trading volume, and the number of trades but reduces price efficiency. Chen, Petkuhov and Wang (2017) show theoretically that, during a market downturn, circuit breakers can cause the magnet effect and increase price volatility ${ }^{3}$

The empirical evidence on the magnet effect is also mixed. Goldstein and Kavajecz (2004) study the order and quote data of the NYSE during the market break on October 27th and 28th, 1997. They find increased order imbalance tilted more towards the supply side rather than the demand side and reduced liquidity on the limit order book when quotes are further away from the best quotes. They also identify the magnet effect when circuit breakers would be imminently triggered. But Abad and Pascal (2007) note that on the Spanish Stock Exchange, in the presence of a call auction automatically used once the limit is triggered, investors trade less aggressively and no magnet effect is observed. Kim, Liu, and Yang (2013) study the Chinese stock market data and find no evidence for the magnet effect in the context of price limits. But they do not offer any evidence for market-wide circuit breakers ${ }^{4}$ Hautsch and Horvath (2019) examine single-stock trading pauses for Nasdaq stocks based on recent regulatory changes in the U.S. markets since 2013 and find that while trading pauses serve

\footnotetext{
${ }^{3}$ Ackert, Church and Jayaraman (2001) show, through their experimental study, that circuit breakers cause the magnet effect.

${ }^{4}$ Some empirical studies find some evidence for the magnet effect of specific forms when price limits are imposed. See Cho, Russell, Tiao, and Tsy (2003) and Hsieh, Kim and Yang (2009) for asymmetric magnet effects; Wong, Chang and Tu (2009) for trading behaviors of small investors that drive the magnet effect; and Wong, Liu and Zeng (2009) for the speed at which the magnet effect occurs.
} 
as safeguards in volatile markets with added protection for market participants who trade against current price movements and initiate trend reversals, the pauses also have the magnet effect on price stability.

As noted by Harris (1998), the existing empirical research rarely has an opportunity to study market-wide circuit breakers that are actually being triggered. The introduction, triggering, and subsequent abandonment of market-wide circuit breakers in the Chinese stock markets in January 2016 provide a valuable and fertile case for studying the magnet effect and the relationship between market-wide circuit breakers and market microstructure.

More recently, Hao (2016), Wong, Kong, and Li (2016), and Yang and Jin (2017) represent the first few studies on market-wide circuit breakers in the Chinese markets and show some evidence for the magnet effect. First, these studies do not examine the magnet effect on market microstructure. Hao (2016) and Wong, Kong, and Li (2016) use the high frequency intraday data but have not yet examined liquidity, order imbalance and investor behaviors, which are the key concerns for policymakers and for testing the magnet effect. Yang and Jin (2017) use primarily the daily data with only the market volatility being calculated based on intraday transactions data. Studying market microstructure requires high frequency intraday data. Second, these studies do not consider the potential bias induced by the interconnections among, and therefore the endogeneity of, those key market microstructure variables. As is known in the econometric literature, the endogeneity of independent variables in a model, if not addressed, bias the estimates of the coefficient estimates of the model. This paper extends these earlier studies by providing a comprehensive analysis of market-wide circuit breakers using an innovative econometric methodology to investigate the effect of circuit breakers on market microstructure.

In our paper, in order to isolate the impacts of circuit breakers, we use high frequency intraday transactions and limit order book data to analyze the change in market microstructure across the event sampl $\biguplus^{5}$ with circuit breakers and the pre-event $t^{6}$ and post-event $t^{7}$ control samples, which mirror the event sample but without any circuit breakers. To test the hypotheses on circuit breakers' "cooling effect" and magnet effect, we build models to capture the interconnections among endogenous market microstructure variables and exogenous policy variables and use significance tests for key parameters in the models to test these hypotheses. We have three innovations in the research methodology. First, we use Lasso IV

\footnotetext{
${ }^{5}$ The sample covers $1 / 4 / 2016-1 / 7 / 2016$.

${ }^{6}$ The sample covers $8 / 18 / 2015,8 / 24 / 2015-8 / 25 / 2015$.

${ }^{7}$ The sample covers $1 / 11 / 2016,1 / 26 / 2016$, and $2 / 25 / 2016$.
} 
models to capture the interconnections among, and therefore the endogeneity of, market microstructure variables and identify a pool of a priori valid instrumental variables (IVs) for an IV estimation based on the econometric literature (see Sargan, 1961; Fair, 1970) and market microstructure literature (see O’Hara, 2003; O’Hara, 2015; Subrahmanyan, 1994). Second, we use Lasso IV to estimate the models so that we can efficiently select, from the pool, strong instrumental variables to deal with the endogeneity encountered in the models (see Belloni et al., 2012; Belloni et al., 2014; Chernozhukov et al., 2015; Lin et al., 2015). Third, by using a test for over-identification, we restrict chosen instrumental variables to those with more lags that are less likely to be endogenous due to inherent intertemporal correlations. This is the joint significance test proposed by Chernozhukov et al. (2013, Appendix M) for Lasso estimation of the auxiliary regression of Lasso IV residuals.

We find that market-wide circuit breakers have no "cooling effect" in decelerating falling prices (or returns) and reducing market volatility and order imbalance. Their presence does not affect bid-ask spreads but causes trades of various sizes to fall in both volume and the number of trades. We find that, as the market index return falls towards the $-5 \%$ (or $-7 \%$ ) threshold, circuit breakers induce significant magnet effects on stock returns, order imbalance, quote imbalance, and trades of various sizes.

This paper is organized as follows: Section 2 introduces the relevant institutional background for market-wide circuit breakers and price limits in Chinese stock markets. Section 3 presents research hypotheses and methodology. Section 4 describes data and empirical results. Section 5 concludes.

\section{Implementation of Circuit Breakers}

\subsection{Market Microstructure: China's Case}

The Shanghai Stock Exchange (SSE) and Shenzhen Stock Exchange (SZSE) are the two stock exchanges in China 8 The two stock exchanges open at 9:30 and close at 15:00 with a lunch break from 11:30 to 13:00. There are four hours of trading per day. There is a pre-trading session from 9:15 to 9:25 each day, during which opening prices are determined. There are no market makers in these stock exchanges as in the NYSE. Instead, both SSE and SZSE use a centralized, scripless, computerized order matching system with both periodic

\footnotetext{
${ }^{8}$ The former was established in November 26th, 1990 while the latter in December 1st, 1990. Over the years, these stock exchanges have grown substantially. See Xu (2000).
} 
and continuous auction methods.

The periodic auction is used in the pre-trading session. The bid prices and lots from the buyer side and ask prices and lots from the seller side are collected to form the demand and supply schedule as show in Figure 1. The morning opening price is determined in the pre-trading session from 9:15 to 9:25 and the price $P^{E}$ will equate the quantity supplied to quantity demanded.

\section{(Please insert Figure 1 about here)}

Once the stock market opens, the continuous and discriminating auction method will be used based on the supply schedule highlighted in Figure 2 and the demand schedule highlighted in Figure 3. The auction is continuous throughout the trading day. When the market closes at 11:30 and restarts at 13:00, the auction will continue without resorting to the periodic auction method. The auction is discriminating in the sense that the orders are placed on the demand and supply schedules on the first-in-first-out basis (FIFO). More specifically, after the morning opening, unmatched buy orders remain to be on the downward demand schedule while unmatched sell orders remain to be on the upward supply schedule. In Figure 2, when a buy order comes to the market at a bid price above $P^{E}$, a sell order between $E$ and $A$ will be matched with the buy order on the FIFO basis and executed at the bid price. When a buy order with bid price below $P^{E}$ cannot be matched, the buy order will not be executed. These unmatched buy orders are accumulated in the book of buy orders. Similarly, when a sell order is placed with an ask price below $P^{E}$, as shown in Figure 3 , a buy order between $E$ and $B$ will be matched with the sell order on the FIFO basis and executed at the ask price. When a sell order with an ask price above $P^{E}$ cannot be matched, the sell order will not be executed. These unmatched orders will be accumulated in the book of sell orders.

(Please Figures 2 and 3 about here)

The above description of market microstructure of the China's stock markets (SSE and SZSE) confirms that the determination of the morning opening price and the prices evolved during the trading day is accurately described by the standard models for the demand and supply. The difference is that during the pre-trading session the segments of the demand and supply schedules to the left of point $E$ are relevant to the determination of price $P^{E}$ while, during the trading day, the segments of the demand and supply schedules to the right 
of point $E$ exists while the other segments would disappear from the exchange as the orders on the other segments have been already executed.

Although, during the trading day, only the segments of the demand and supply scheduled to the right of point $E$ are observable as shown in Figures 2 and 3 , the demand and supply schedules are indeed reflected in the limit order book (like the level II quotation system in the developed stock markets). If there is a parallel shift of the demand schedule to the right, then it will lead to a higher price $P^{E}$ and a higher volume $Q^{E}$, ceteris paribus. Similarly, if there is a parallel shift of the supply schedule to the left, this will lead to a higher price $P^{E}$ and a lower volume $Q^{E}$, ceteris paribus. In addition to the parallel shifts of the above kinds, the demand and supply schedules can be shifted in other ways.

With the intraday transactions data, we will be able to evaluate not only the price and volume information on intraday transactions but also the buy and sell volumes and the buy and sell trades with various sizes. In the intraday transactions data, because we can identify which party - the buyer or the seller - initiates the trade resulting in a transaction, we can calculate the order imbalance in volume measured by the difference between the volume of buys and the volume of sells. The positive (negative) order imbalance in volume indicates more (less) buy volume than sell volume. We can also calculate the order imbalance in the number of trades measured by the difference between the number of buy trades and the number of sell trades. The positive (negative) order imbalance in the number of trades indicates more (less) buy trades than sell trades. With the intraday limit order book's quote data, we will be able to obtain the intraday data for the first five best ask and bid prices, and the first five best ask and bid volumes. These intraday data contain rich information about market microstructure. For example, the bid-ask spread in price carries the information about the gap in bid and ask prices while the bid-ask quote imbalances in volume carries the information about the gap in bid and ask volumes.

As can be seen from the above setting, the buy and sell orders (limit prices and volumes) lined up on the demand and supply schedules on the right of the previous transaction price, $P^{E}$, and volume, $Q^{E}$, will represent the market forces driving the price discovery process. When the gap between the bid and ask prices and the gap between the bid and ask volumes are large, if transactions occur we would expect the realized return volatility to be greater. As shown in the paper, our intraday transactions and limit order book data provide rich information for the analysis of market microstructure.

In the Chinese stock markets, price limits have been implemented for individual stocks 
since December 26th, 1996.9 The individual stock price cannot move beyond the imposed price limits of $\pm 10 \%$ of the previous day's closing price 10 But once the price limits have been reached, trading at the price limits or within the limits $( \pm 10 \%)$ can continue till the end of the trading day. Chen, Rui, and Wang (2005) find that the imposition of price limits can reduce market volatility of the trading day during the bear market but not the bull market ${ }^{11}$ More recently, Kim, Liu, and Yang (2013) find that price limits reduce price volatility. The imposition of market-wide circuit breakers on top of the price limit mechanism in China, although it was short-lived, provides a unique natural experiment for studying the impacts of both price limits and market-wide circuit breakers. ${ }^{12}$ This research will enhance our understanding on how market-wide circuit breakers affect market microstructure in the presence of price limits.

\subsection{Implementation of Circuit Breakers}

The institutional characteristics of the Chinese stock markets make this study unique compared to stock markets in other countries. First, the Chinese stock markets represent the largest stock market emerged from the previously central planning system through a profound reform process towards the market system.13, ${ }^{14}$ Second, the investors in the Chinese stock markets are more incentivized to trade as there is no tax imposed on capital gains

\footnotetext{
${ }^{9} \mathrm{Kim}$, Liu and Yang (2013) note that the Chinese stock markets had experimented with a variety of price limit ranges before the $\pm 10 \%$ price limits were adopted. In 1990 when the SSE and SZSE were opened, price limit regulations were different between the two exchanges. Price limits on the SSE (SZSE) were initially set at $3 \%(10 \%)$. Over the course of the following two years, price limit ranges varied from $0.5 \%$ to $5 \%$. During 1992 - 1996, both markets eliminated price limits, and both markets reimposed them at the end of 1996.

${ }^{10}$ We do not study ST stocks which are under "special treatment" due to poor financial performance and are excluded from the CSI 300 Index. The ST stocks are often under the watch and their price limits are lower, at $\pm 5 \%$.

${ }^{11}$ Kim and Yang (2004) survey the literature that shows mixed findings on volatility but a confirming evidence on price discovery.

${ }^{12}$ Under the revised rules approved by the SEC in 2012 in the U.S. stock market, market-wide circuit breakers kick in when the S\&P 500 Index drops 7 percent (Level 1), 13 percent (Level 2), and 20 percent (Level 3) from the prior day's close (see NYSE Arca Equity Rules-Rule 7.12. Trading Halts Due to Extraordinary Market Volatility). A $\pm 10 \%$ price limit is imposed on the experimental basis on all stocks included in the S\&P 500 Index, Russell 1000 Index, and a pilot list of exchange traded funds at January 19th, 2017 (NYSEArca-2016-130).

${ }^{13}$ Different from most mature markets where stock trading tends to be dominated by informed institutional investors, stock trading tends to be dominated by less-informed retail investors in emerging markets. As liquidity-driven trades would cause higher prices volatility (e.g., Grossman and Miller, 1988) and reduce market liquidity, the impacts of circuit breakers on market microstructure might be more prominent.

${ }^{14}$ In May 2012, the United States introduced price limits on individual stocks (effective on April 8th, 2013). If trading orders for a stock are placed at a price $5 \%$ above or below the average price from the preceding five minutes, the order is not executed and a five-minute trading halt follows.
} 
through stock trading and therefore the markets can be highly volatile. ${ }^{15}$ Third, the marketwide circuit breakers - $\pm 5 \%$ at Level 1 and $\pm 7 \%$ at Level 2 - were set much lower than the price limit for individual stocks in China $( \pm 10 \%)$ and could well be triggered before a significant number of individual stocks trigger their price limits ${ }^{16}$

The background for the circuit breakers' proposal can be traced back to the period from the second quarter of 2015 to the first quarter of 2016. During this period, Caixin Media's China Purchasing Managers' Index (PMI), a closely watched gauge of nationwide manufacturing activity, fall from the level above 50 to a low below 48 (see Figure 4). Corresponding to the worsening economic conditions, during June 2015, the Chinese stock market started to decline. In August 2015, the Chinese stock markets experienced sharp falls in some trading days. The CSI 300 Index fell $-6.19 \%,-8.99 \%$, and $-7.68 \%$ on August 18th, 24th, and 25th, 2015, respectively (see Figures 5 7). The latter two days are referred to as "Black Monday" and "Black Tuesday".

(Please insert Figure 4 and Figures 54 about here)

In anticipation of possible further market crashes and market instability, in the evening of September 7th, 2015, the SSE, SZSE, and China Financial Futures Exchange (CFFE) said in their news release: "With reference to the Provisions of the Relevant Index Circuit Breaker Public Consultation Notice, to guard against market volatility risk, to further improve the trading mechanism of China's securities market, to maintain market order and protect the interests of investors, and to promote long-term stable and healthy development of the securities market, the China Securities Regulatory Commission agreed that the Shanghai Stock Exchange, Shenzhen Stock Exchange and the China Financial Futures Exchange intend to retain the existing price system for stocks under the premise of the introduction of index circuit breaker mechanism." The overall index circuit breaker mechanism has the following arrangements: "When the rise or decline of the CSI 300 Index reaches a certain threshold, all stocks, convertible bonds, bonds with detachable warrants, stock options and other stock related instruments listed on the Shanghai and Shenzhen Stock Exchanges will be suspended from trading and all stock index futures contracts on the China Financial Futures Exchange

\footnotetext{
${ }^{15}$ There is no tax imposed on capital gains in mainland China, Hong Kong and Taiwan. Capital gains tax was introduced in Taiwan in 2012 but was subsequently eliminated in 2015 (see "Revoking of capital gains tax approved", Taipei Times, Wednesday, Nov 18th, 2015, Page 1).

${ }^{16}$ George and Hwang (1995) study the role of price limits and find that price limits affect volatility in the context where there are no market-wide circuit breakers.
} 
will be suspended from trading. After the suspension of trading hours, as the case warranted, these markets may resume trading or directly be closed." "The index circuit breaker mechanism has two circuit breaker thresholds $5 \%$ and $7 \%$ changes of the index."

On December 4th, 2015, the China Securities Regulatory Commission (CSRC) announced that the SSE, SZSE, and $\mathrm{CFFE}^{17}$ would implement the proposed market-wide circuit breakers on January 1st, 2016 ${ }^{18}$ Based on the feedback comments, the formal Notice had shortened the suspension of trading from 30 to 15 minutes once the stock exchanges trigger the $-5 \%$ threshold (the Level 1 circuit breaker) but retained the suspension till the end of trading day if the $-5 \%$ threshold is triggered at the later part of the trading day or if the $-7 \%$ threshold (Level 2 circuit breaker) is triggered at any time of the trading day. Apparently, the authorities of the three exchanges did not expect large fluctuations in the three exchanges as the formal Notice indicates: "From the experiences from other stock markets, the stock markets in the United States, South Korea, India and other countries had not triggered their highest circuit breaker threshold so that they need to suspend trading or close the market" while "[t]he purpose of higher thresholds is designed to guard against systemic risk." However, the market participants in China had raised doubts on whether the existing threshold is too narrow so that more frequent trading halts might be triggered and whether the two circuit breakers are set too close to each other so that trading halts may be triggered continuously. They suggest that "only one threshold is established or the interval between the two thresholds to be widened to $6 \%$ and $8 \%$."19 But the authorities of the Chinese stock exchanges believe that "the two implemented $5 \%$ and $7 \%$ thresholds are based on the analysis of historical data of the past 11 years." Implicitly, the authorities of the three exchanges believed that these final market-wide circuit breakers are reasonable.

On December 31st, 2015, the last trading date of the year, the CSI 300 Index fell (see Figure 8). During the period of January 4th-7th, 2016, the CSI 300 Index fell again and triggered the circuit breakers on January 4th, 2016 and January 7th, 2016, right after the implementation of the circuit breakers (see Figures 9 12). As shown in Figure 9, on Monday, January 4th, 2016, the CSI 300 Index fell 5\% at 13:12 and the three exchanges were suspended from trading for 15 minutes based on the newly-implemented circuit breakers rules. After the three exchanges resumed trading at 13:27, the CSI 300 Index fell again. At 13:43, the

\footnotetext{
${ }^{17}$ We refer the SSE, SZSE, and CFFE as the three exchanges in the paper.

${ }^{18}$ Due to the New Year holidays, the market-wide circuit breakers started to be implemented on January 4th 2016 when the stock markets in China were reopened after these holidays.

${ }^{19}$ See Xia Chun, "Pros and Cons of the Circuit Breakers in Financial Markets," Financial Times (Chinese Edition), December 10th, 2016, http://www.ftchinese.com/story/001065202
} 
CSI 300 Index fell 7\% and the exchanges stopped trading and were closed. As shown in Figures 10 and 11, the trading on January 5th and 6th was volatile but did not trigger any circuit breakers. As shown in Figure 12, on January 7th, 2016, both the SSE and SZSE opened lower during the first 15 minutes of the trading day. The CSI 300 Index fell 5\% at 9:42, triggering the Level 1 circuit breaker. After a trading halt for 15 minutes, at about 9:57 the CSI 300 Index fell 7\% triggering Level 2 circuit breaker. Based on the new rules, the three exchanges halted trading and were closed after the markets re-opened only for 15 minutes.

(Please insert Figures 812 about here)

The fact that circuit breakers were triggered twice on January 4th and 7th, 2016 alarmed the stock market participants in China. Immediately after the event, approved by the CSRC, SSE decided to suspend the implementation of the new circuit breaker mechanism on January 8th, 2016. As shown in Figure 13, on January 8th, 2016, the CSI 300 Index stabilized approximately around the level of 3550. Because of the unchanged economic fundamentals, the stock market was hovering at a lower level, the CSI 300 Index fell sharply again on January 11th and 26th, and February 25th, 2016 before the CSI 300 Index moved into a recovery phase (see Figures 13 16).

(Please insert Figures 13,16 about here)

\section{Hypotheses and Methodology}

\subsection{Hypotheses}

In this paper, we post and test following hypotheses about the impacts of market-wide circuit breakers on key market microstructure variables.

The first null hypothesis is that market-wide circuit breakers have no "cooling effect" in decelerating falling prices (or returns), reducing market volatility and order imbalance, and increasing trading activities in volume and trades. The alternative hypothesis is that market-wide circuit breakers have the "cooling effect". The previous research (Kuhn, Kuserk, and Locke 1991; Gerety and Mulherin, 1992; Lauterbach and Ben-Zion 1993; Goldstein and Kavajecz, 2004; and Wong, Chang, and Tu, 2009) provides mixed findings. More recently, Kim, Liu, and Yang (2013) show that price limits moderate market volatility but have not 
examined the impacts of market-wide circuit breakers on volatility. Hao (2016) and Wong, Kong, and Li (2016) study the market-circuit breakers, but they do not consider order imbalance.

The second null hypothesis is that market-wide circuit breakers have no impact on liquidity such as spread and depth. The alternative hypothesis is that market-wide circuit breakers have an impact on liquidity. Grossman and Miller (1988) suggest that order imbalance and higher demand for intermediacy would cause the market to crash. Greenwald and Stein (1991) suggest that circuit breakers could deal with the problem of lack of liquidity. Hao (2016) and Wong, Kong, and Li (2016) study the market-circuit breakers, but they do not consider liquidity.

The third null hypothesis is that market-wide circuit breakers have no impact on sizes of trades in terms of volume and the number of trades. The alternative hypothesis is that market-wide circuit breakers have an impact on sizes of trades. Subrahmanyam (1994) predicts that large strategic traders would divide large orders into smaller ones and advance their trades as the circuit breaker thresholds are to be triggered or submit large orders suboptimally in a concentrated fashion to ensure their ability to trade. $\mathrm{Ng}$ and $\mathrm{Wu}$ (2007) point out that the institutional investors in the Chinese stock markets are momentum traders while the individual traders in the market are contrarian traders. Wong, Chang, and Tu (2009) find that the uninformed traders in the Taiwan Stock Exchange, when facing price limits, trade more aggressively causing the magnet effect. Lee, Li, and Wang (2010) find that less-informed individual investors respond to return shocks more than institutional investors do in China. Hao (2016) and Wong, Kong, and Li (2016) study the market-circuit breakers, but they do not consider sizes of trades.

The fourth null hypothesis is that market-wide circuit breakers have no magnet effect on stock returns. The alternative hypothesis is that market-wide circuit breakers have a magnet effect. Subrahmanyam (1994) predicts that circuit breakers have the magnet effect on stock returns. Cho, Russell, Tiao, and Tsy (2003) and Chen, Rui and Wang (2005) find that price limits in the greater China region (including Taiwan and mainland China) have the magnet effect in that the prices accelerate to the upper and lower bounds but not symmetrically. But Kim, Liu, and Yang (2013) find that price limits in China have no magnet effect. We do not know if market-wide circuit breakers have any magnet effect in the presence of price limits. Hao (2016) focuses on the magnet effect of market-wide circuit breakers on stock returns in a DID AR(3)-GARCH(1,1) model across the treatment and control samples. He relies on a binary indicator to find a weak magnet effect, but he does not consider endogeneity. Wong, 
Kong, and $\mathrm{Li}$ (2016) use the reaction of a $\mathrm{AR}(3)-\mathrm{GARCH}(2,2)$-filtered standardized return to circuit breakers and find the magnet effect, but they do not consider the control sample(s) and endogeneity.

\subsection{Methodology}

To test the four hypotheses, we take note of three classes of variables of interest. ${ }^{20}$

First, we use the column vector $\mathbf{Y}_{t}$ to denote $p$ variables of current trade and quote information at time $t$. The variables of current trade information include the CSI 300 Index return (RCSI300), ${ }^{21}$ volatility (RV.STK) ${ }^{22}$ trading volume (VOLUME) ${ }^{23}$ the number of trades (NTRADE), order imbalance in volume (OIB.VOL) ${ }^{24}$ order imbalance in trades (OIB.TRD) 25 trading volumes of small-, mid-, and large-sized trades (VOL.SML, VOL.MID, and VOL.LRG) ${ }^{26}$ and the numbers of trades of small-, mid-, and large-sized trades (TRD.SML, TRD.MID, and TRD.LRG). The variables of current quote information describing liquidity (spread and depth) include the first three best bid-ask spreads in price (RSPREAD1, RSPREAD2, and RSPREAD3) ${ }^{27}$ and the first three best bid-ask quote imbalances in volume (QIM1, QIM2, and QIM3) derived from, respectively, the differences between the first three best pairs of bid and ask volumes (BIDVOL1 and ASKVOL1, BIDVOL2 and ASKVOL2, and BIDVOL3 and ASKVOL3). All $p$ variables in $\mathbf{Y}_{t}$ are endogenous at time $t$.

Second, we use two control variables $\mathrm{POST}_{t}$ and $\mathrm{CIRCUIT}_{t}$ for the post-event control sample and the event-sample, respectively. Here, $\mathrm{POST}_{t}=1\left(\mathrm{CIRCUIT}_{t}=1\right)$ if the sample is the post-event control (event) sample; $\mathrm{POST}_{t}=0\left(\mathrm{CIRCUIT}_{t}=0\right)$ otherwise. These

\footnotetext{
${ }^{20}$ See Appendix $\mathrm{A}$ for the definitions of the all, intermediate and final, variables.

${ }^{21} \mathrm{RCSI} 300$ is the percentage change of, or the return on, the CSI 300 Index at fixed time (e.g., 5-minute) intervals relative to the CSI 300 Index at corresponding time intervals in the previous trading day. This variable defines circuit breakers' Level $1( \pm 5 \%)$ and Level $2( \pm 7 \%)$ thresholds and serves as a benchmark return of the market index when we evaluate the magnet effect and other features of market microstructure.

${ }^{22}$ RV.STK is the average realized volatility of the stocks in the CSI 300 Index. We construct this model-free volatility measure following Andersen et al. (2001).

${ }^{23}$ Trading volume is the average number of stocks traded per stock in round lots (100 shares) for all stocks in the CSI 300 Index.

${ }^{24}$ This refers to the difference in trading volumes initiated by buyers and sellers.

${ }^{25}$ This refers to the difference in the number of trades initiated by buyers and sellers.

${ }^{26}$ Consistent with $\mathrm{Ng}$ and $\mathrm{Wu}(2007)$, in this research, a small-sized trade has the total value less than 10,000 RMB, a middle-sized or mid-sized trade has the total value greater than or equal to 10,000 RMB but less than 50,000 RMB, and a large-sized trade has the total value of a trade at 50,000 RMB or more. As noted by Koski and Michaely (2000) and Dhaliwal and Li (2006), trade sizes have their own information contents.

${ }^{27}$ The relative bid-ask spread is defined as the difference in absolute value between the bid and ask prices relative to their average or the difference between the ask and bid prices relative to their average.
} 
two indicator variables are exogenous for all $t$. When $\mathrm{CIRCUIT}_{t}=0$ and $\mathrm{POST}_{t}=0$, it represents the baseline case for the pre-event control sample.

Third, we use $\Omega_{t-j}^{t-L}=\left\{\mathbf{Y}_{t-j}, \ldots, \mathbf{Y}_{t-L}\right\}$ to denote the lagged variables for past trade and quote information from $t-j$ to $t-L$, where $j \geq 1$ and $j<L$. The lagged endogenous variables in $\Omega_{t-1}^{t-L}$ can be viewed as a pool of a priori valid instrumental variables. Once the variables in $\mathbf{Y}_{t-j}, j=1,2, \ldots, L$, are determined jointly in the market at time $t-j$, they become the recorded history and will not be affected in any fashion by the trade and quote information at time $t, \mathbf{Y}_{t}$. We will explain how to ensure the selected instrumental variables from the pool are strong and exogenous later in details.

To evaluate the impacts of market-wide circuit breakers on market microstructure, we propose the model for the dependent variable $Y_{i, t}$ (say, the CSI 300 Index return, RCSI300), the $i$ th variable in $\mathbf{Y}_{t}$. This model includes following independent variables. First, the model includes all $p-1$ endogenous variables (say, volatility, trading volume, the number of trades, and so on) in $\mathbf{Y}_{t}$ except $Y_{i, t}$, denoted by $\mathbf{Y}_{-i, t}$, to capture the contemporaneous interconnections among the endogenous variables at time $t$. Second, the model includes $\mathrm{GAP}_{t}$ and $\mathrm{GAP}_{t}$ as in Cho, Russell, Tiao and Tsay (2003), Du, Liu and Rhee (2009), and Wong, Liu and Zeng (2009). If the CSI 300 Index return falls $2 \%$ (or 4\%) or more but no more than the $-5 \%$ (or $-7 \%$ ) threshold (i.e., the 3 percentage point window for the $-5 \%$ (or $-7 \%$ ) threshold herein), GAP $5_{t}\left(\mathrm{GAP} 7_{t}\right)$ is the absolute value of the difference in percentage points between the falling CSI 300 Index return and the $-5 \%$ (or -7\%) threshold; otherwise, $\mathrm{GAP}_{t}\left(\mathrm{GAP}_{t}\right)$ is assigned zero ${ }^{28}$ Third, the model contains $\mathrm{POST}_{t}$ and $\mathrm{CIRCUIT}_{t}$ as defined previously. Fourth, the model contains the cross-product terms between $\mathrm{POST}_{t}$ and $\mathrm{GAP}_{t}\left(\mathrm{GAP}_{t}\right)$ and between CIRCUIT $t$ and GAP5 $5_{t}\left(\mathrm{GAP}_{t}\right)$. Finally, the model for $Y_{i, t}$ also contains the random error $u_{i, t}$. The model for $Y_{i, t}$ can be written as

$$
\begin{gathered}
Y_{i, t}=\alpha_{i}+\mathrm{Y}_{-i, t}^{\prime} \beta_{i}+\gamma_{i, 1} \mathrm{POST}_{t}+\gamma_{i, 2} \mathrm{CIRCUIT}_{t}+\kappa_{i, 1} \mathrm{GAP}_{t}+\kappa_{i, 2} \mathrm{GAP}_{t} \\
+\eta_{i, 1}\left(\mathrm{POST}_{t} * \mathrm{GAP}_{t}\right)+\eta_{i, 2}\left(\mathrm{POST}_{t} * \mathrm{GAP}_{t}\right)+\delta_{i, 1}\left(\mathrm{CIRCUIT}_{t} * \mathrm{GAP}_{t}\right) \\
+\delta_{i, 2}\left(\mathrm{CIRCUIT}_{t} * \mathrm{GAP}_{t}\right)+u_{i, t} .
\end{gathered}
$$

Here, $\alpha_{i}$ is the intercept parameter. $\beta_{i}$ associated with $\mathbf{Y}_{-i, t}$ is a vector of coefficients capturing the interconnections between $Y_{i, t}$ and $\mathbf{Y}_{-i, t}$.

\footnotetext{
${ }^{28} \mathrm{GAP}_{t}\left(\mathrm{GAP}_{t}\right)$ is, therefore, a local impulse function measuring how close the CSI 300 Index return is to the $-5 \%$ (or $-7 \%$ ) threshold when the CSI 300 Index return falls towards the $-5 \%$ (or $-7 \%$ ) threshold.
} 
$\gamma_{i, 1}\left(\gamma_{i, 2}\right)$ associated with POST $_{t}\left(\right.$ CIRCUIT $\left._{t}\right)$ measures the fixed effect of the post-event control (event) sample without (with) circuit breakers on $Y_{i, t}$. Note that $\gamma_{i, 2}$ indicates the market behavior when the circuit breakers $\left(\right.$ CIRCUIT $\left._{t}\right)$ are imposed in the event sample. A statistically significant estimate of $\gamma_{i, 2}$ represents a different market behavior induced by circuit breakers in the event sample.

$\kappa_{i, 1}\left(\kappa_{i, 2}\right)$ associated with GAP $5_{t}\left(\mathrm{GAP}_{t}\right)$ measures the net impact of the gap between the falling CSI 300 Index return and $-5 \%$ (or $-7 \%$ ) threshold on $Y_{i, t}$ for the pre-event control sample. $\eta_{i, 1}\left(\eta_{i, 2}\right)$ associated with $\mathrm{POST}_{t} * \mathrm{GAP}_{t}\left(\mathrm{POST}_{t} * \mathrm{GAP}_{t}\right)$ measures the net impact of the gap between the falling CSI 300 Index return and the $-5 \%$ (or $-7 \%$ ) threshold on $Y_{i, t}$ in the post-event control sample. Note that $\kappa_{i, 1}\left(\kappa_{i, 2}\right)$ and $\eta_{i, 1}\left(\eta_{i, 2}\right)$ indicate the market behavior towards the $-5 \%$ (or $-7 \%$ ) threshold with no circuit breakers in the pre- and post-event control samples, respectively. Therefore, GAP $5_{t}$ and $\mathrm{GAP} 7_{t}$ for the pre-event control sample and $\mathrm{POST}_{t} * \mathrm{GAP}_{t}$ and $\mathrm{POST}_{t} * \mathrm{GAP}_{t}$ for the post-event control sample are actually pseudo circuit breakers for those samples in the spirit of Lee, Ready and Sequin (1994).

$\delta_{i, 1}\left(\delta_{i, 2}\right)$ associated with $\mathrm{CIRCUIT}_{t} * \mathrm{GAP}_{t}\left(\mathrm{CIRCUIT}_{t} * \mathrm{GAP}_{t}\right)$ measures the net impact of the gap between the falling CSI 300 Index return and the $-5 \%$ (or $-7 \%$ ) threshold on $Y_{i, t}$ in the event sample with circuit breakers. A statistically significant estimate of $\delta_{i, 1}$ $\left(\delta_{i, 2}\right)$ represents the magnet effect induced by the $-5 \%$ (or $-7 \%$ ) threshold in the event sample.

The independent variables of the model such as $\mathbf{Y}_{-i, t}, \mathrm{GAP}_{t}, \mathrm{GAP} 7_{t}$, and all other variables that contain either $\mathrm{GAP}_{t}$ or $\mathrm{GAP}_{t}$ are endogenous. To make reliable statistical inference, we must use an IV method to estimate the model with strong and exogenous instrumental variables.

The variables in $\Omega_{t-j}^{t-L}$ form a good pool of a priori valid instrumental variables. In the econometrics literature on simultaneous equation models, predetermined endogenous variables are treated as exogenous and hence can be used as a priori valid instrumental variables (see, for example, Sargan, 1961; Fair, 1970). The microstructure literature recognizes that while the traders use, although they cannot change, past trade and quote information to trade or place their orders in the limit order book, transaction prices can differ widely within a very short time span (see O'Hara, 2003, p. 1351). This unpredictability, consistent with the traditional random walk hypothesis, is often coined as "the risk aspect of price discovery" (see O'Hara, 2003, p. 1342). Hence, the variables for past trade and quote information can be used as a priori valid instrumental variables, although not all of them are equally desirable.

Some of these a priori valid instrumental variables may not be strong, we need to select, 
from all a priori valid instrumental variables, those instrumental variables that are strongly correlated with the endogenous variables using Lasso IV estimation (see Belloni et al., 2012; Belloni et al., 2014; Chernozhukov et al., 2015; and Lin et al., 2015) ${ }^{29}$ Lasso IV estimation selects strong instrumental variables and produce larger Wald test values in the first stage of estimation and smaller standard errors in the second stage of estimation (see Belloni et al., 2012). As the result of Lasso IV estimation, we can select $L$ for $\Omega_{t-1}^{t-L}$ so that all strong instrumental variables should be selected.

Even if the selected instrumental variables are strong, some of them may not be exogenous as desired. The strong and exogenous instrumental variables in $\Omega_{t-j}^{t-L}$, for some $j$, cannot affect $Y_{i, t}$ or $u_{i, t}$ in the model directly but can affect $Y_{i, t}$ only through the included endogenous variables. While the transaction prices can be unpredictable as "the risk aspect of price discovery" (see O'Hara, 2003) given past trade and quote information, Subrahmanyan (1994) and O'Hara (2015) also note that traders could trade strategically, through a sequence of orders in trading, to take the advantage of expected circuit breakers or profitable opportunities. This implies that the variables of trade and quote information may be intertemporally correlated up to order $s$ within a very short time span. Therefore, to ensure the chosen instrumental variables to be exogenous for the model, they must have sufficient lags. Thus, we need to further restrict our instrumental variables in $\Omega_{t-1}^{t-L}$ to $\Omega_{t-j}^{t-L}$, where $j>s$ and $j<L$. For example, if the variables in $\mathbf{Y}_{t}$ are autoregressive of order $s=1$, assigning $j=2>s=1$ would remove $\mathbf{Y}_{t-1}$ from $\Omega_{t-1}^{t-L}$ resulting $\Omega_{t-2}^{t-L}$. This exclusion ensures the remaining instrumental variables in $\Omega_{t-2}^{t-L}$ to be exogenous. In our empirical work, given that our models are over-identified with many strong instrumental variables, we use the joint significance test for Lasso estimation of the auxiliary regression of Lasso IV residuals on instrumental variables and control variables to check if all instrumental variables are exogenous ${ }^{30}$

\footnotetext{
${ }^{29}$ Lasso IV estimation involves the two stages as in 2SLS estimation. The first stage of Lasso IV estimation of each endogenous variable on instrumental variables is based on the use of Lasso and post-Lasso. Lasso estimates regression coefficients by minimizing the sum of the usual least squares objective function and a penalty for model size through the sum of the absolute values of the coefficients (see Belloni et al., 2012). The resulting Lasso estimator selects instrumental variables and estimates the first-stage regression coefficients via a shrinkage procedure. The post-Lasso estimator discards the Lasso coefficient estimates and uses the data-dependent set of instrumental variables selected by Lasso to refit the first-stage regression via ordinary least squares (OLS) with heteroscedastic errors to alleviate Lasso's shrinkage bias. Then, the fitted values of the endogenous variables are then used in the second stage of Lasso IV estimation via OLS.

${ }^{30}$ This test is in the same spirit of the Sagan test. See the joint significance test proposed by Chernozhukov et al. (2013, Appendix M).
} 


\section{Data and Empirical Results}

\subsection{Data}

Following Corwin and Lipson (2000), we select the event sample that covers January 4thJanuary 7 th, 2016, during which the $-5 \%$ and $-7 \%$ circuit breakers were imposed and triggered by the falling market index. We select the pre-event control sample to cover August 18th, 24th, and 25th, 2015 and select the post-event control sample to cover January 11th and 26th and February 25th, 2016, during which no market-wide circuit breakers were imposed but either $-5 \%$ threshold, or $-7 \%$ threshold, or both were triggered by the falling market index.

We obtain the high-frequency intraday transactions and limit order book data for the CSI 300 Index and its constituent stocks for August 2015 and January-February 2016 from the SSE and SZSE via Shanghai Big Data Service Co., Ltd. The CSI 300 Index consists of the 300 constituent stocks that are of the largest market capitalization and are most liquid among all A-share companies listed on the SSE and SZSE. The intraday data contain the information about the index level and trading volumes and transaction values of all 300 constituent stocks. The intraday quote data on individual stocks include securities code, the listing exchange, date, a time stamp updated approximately every 3 seconds, five highest bid prices and five lowest ask prices, and the aggregated total bid- and ask-volumes quoted during the 3 -seconds interval in round lots of 100 shares. The intraday tick-by-tick transactions data record securities code, the listing exchange, date, a time stamp recorded to the nearest second (real time), transaction price, volume and trade direction (buy or sell). An important feature of the transactions data is that the trade direction for each transaction is available, allowing accurate measurement of order imbalance in the Chinese stock markets rather than relying on the algorithm-based classification of trades as in Lee and Ready (1991). Before we proceed with our analysis, we scan the data for errors by searching for large intraday price reversals. We exclude odd lot transactions of less than 100 shares from our analysis 31 The minimum trade size for stock purchases on the SSE and SZSE is 100 shares and odd lot sales are often caused by orders that are filled by multiple counter-parties. During January 2016, 13 stocks in the CSI 300 Index are under temporary trading suspensions and are excluded from our analysis.

Table 1 reports the summary statistics of the remaining 287 stocks on January 4 th and

\footnotetext{
${ }^{31}$ The odd lots account for about $0.07 \%$ of the total trades.
} 
7th, 2016 when circuit breakers are triggered. Table 1 indicates that the CSI 300 stocks are highly liquid with mean daily trading volume of 40 million shares, trading value of RMB 507 million (the average exchange rate is RMB 6.5744 per USD in January 2016), and the number of trades of 21,944 trades per stock. The total number of transactions for our analysis is 6.3 million and 1.8 million transactions on January 4th and 7th, 2016, respectively. Table 1 also shows that when the CSI 300 Index falls to and triggers the $-7 \%$ circuit breaker on January 4th and 7th, 2016, the individual stock prices show similar distributions of means (-8.19\%, $-8.33 \%)$, medians $(-8.90 \%,-9.10 \%)$ and standard deviations $(1.89 \%, 1.99 \%)$ for these two trading days, respectively.

(Please insert Table 1 about here)

\subsection{Implementation of Lasso IV Estimation}

We implement Lasso IV estimation of the models and, based on the estimation results of these models, we test our four hypotheses.

A priori valid instrumental variables in $\Omega_{t-j}^{t-L}$ for the Lasso estimation are lagged market microstructure variables RCSI300, RV.STK, VOLUME, NTRADE, OIB.VOL, OIB.TRD, RSPREAD1, RSPREAD2, RSPREAD3, QIM1, QIM2, QIM3, BID1VOL1, ASKVOL1, BIDVOL2, ASKVOL2, BIDVOL3, and ASKVOL3 with $j$ to $L$ lags from $t$. In the first stage of Lasso IV estimation, based on the Lasso regression of each endogenous variable on all a priori valid instrumental variables, we can identify the common range of lags of the variables in $\Omega_{t-j}^{t-L}$, from $j=1$ to $L=6$, so that strong instrumental variables are included.

To ensure all strong instrumental variables are indeed exogenous, we exclude the instrumental variables that have shorter lags considering intertemporally correlations existing in the variables of trade and quote information in a very short time span. Usually, when models are over-identified, one can use the Sargan test for over-identifying restrictions to check if instrumental variables are indeed exogenous. The Sargan test is based on the auxiliary regression of IV residuals on all instrumental variables and control variables. In our research, we use many instrumental variables and some control variables in Lasso IV estimation and our auxiliary regression of Lasso IV residuals on instrumental variables and control variables must be estimated by Lasso. Therefore, we use the joint significance test for Lasso estimation of the auxiliary regression to check if instrumental variables are indeed exogenous (Chernozhukov et al. 2013, Appendix M). This joint significance test is equivalent to the Sargan test for over-identifying restrictions in IV estimation. Using this test, we find that 
the instrumental variables with $4-6$ lags (i.e., the instrumental variables in $\Omega_{t-4}^{t-6}$ ) would satisfy the over-identification restrictions for the Lasso IV models for RV.STK, RSPREAD1, RSPREAD2, and RSPREAD3 and that the instrumental variables with 2-6 lags (i.e., the

instrumental variables in $\Omega_{t-2}^{t-6}$ ) would satisfy the over-identification restrictions for the Lasso IV models for RCSI300, OIB.VOL, OIB.TRD, VOLUME, NTRADE, QIM1, QIM2, QIM3, VOL.SML, VOL.MID, VOL.LRG, TRD.SML, TRD.MID, and TRD.LRG.

\subsection{Returns, Volatility, Order Imbalances, and Trading Activities}

We first evaluate the interconnections among the market microstructure variables and then test the first null hypothesis that circuit breakers have no "cooling effect".

To capture the interconnections among the market microstructure variables, we estimate Lasso IV models using RCSI300, RV.STK, OIB.VOL, OIB.TRD, VOLUME, and NTRADE as dependent variables.

As shown in Table 2, RCSI300 is significantly correlated with endogenous variables VOLUME, NTRADE, RSPREAD1, RSPREAD2, RSPREAD3, QIM1, QIM2, and QIM3 except RV.STK. RV.STK is significantly correlated with endogenous variables, RCSI300, VOLUME, RSPREAD1, RSPREAD2, and RSPREAD3 but not others. As shown in Table 3. OIB.VOL is significantly correlated with endogenous variables RCSI300 and NTRADE, while OIB.TRD is significantly correlated with endogenous variables RCSI300, NTRADE, QIM1 and QIM3. As shown in Table 4, VOLUME is significantly correlated with endogenous variables RCSI300, RV.STK, NTRADE, RSPREAD1, RSPREAD2, RSPREAD3, and QIM1 except QIM2 and QIM3. NTRADE is significantly correlated with endogenous variables VOLUME and RSPREAD3 but not others.

From the above observations, we note that the CSI 300 Index return and trading activities in volume contain more information and have a stronger link with all other market microstructure variables.

\section{(Please insert Tables 24 about here)}

To test the first null hypothesis that circuit breakers have no "cooling effect" in decelerating falling prices (or returns), reducing market volatility and order imbalance, and increasing trading activities in volume and trades, we use the Lasso IV models with RCSI300, RV.STK, OIB.VOL, OIB.TRD, VOLUME, and NTRADE as dependent variables. The coefficient $\gamma_{i, 2}$ for independent variable CIRCUIT captures the "cooling effect" of circuit breakers on each 
of these dependent variables. Under the first null hypothesis of no "cooling effect", the coefficient $\gamma_{i, 2}$ in the model for RCSI300, denoted as $\gamma_{\mathrm{RCSI} 300,2}$, should be less than or equal to zero; the coefficient $\gamma_{i, 2}$ in the model for RV.STK, denoted as $\gamma_{\mathrm{RV} . \mathrm{STK}, 2}$, should be greater or equal to zero; the coefficients $\gamma_{i, 2}$ 's in the models for OIB.VOL and OIB.TRD, denoted as $\gamma_{\text {OIB.VOL }, 2}$ and $\gamma_{\text {OIB.VOL,2 }}$, should be non-zero; and the coefficients $\gamma_{i, 2}$ 's in the models for VOLUME and NTRADE, denoted as $\gamma_{\text {VOLUME,2 }}$ and $\gamma_{\mathrm{NTRADE}, 2}$, should be less than or equal to zero.

Table 2 shows that the estimated $\gamma_{\text {RCSI300,2 }}$ in the model for RCSI300 is negative and statistically significant at the 0.01 level while the estimated $\gamma_{\mathrm{RV} . S T K, 2}$ in the model for RV.STK is statistically insignificant. This result indicates that, consistent with the first null hypothesis, circuit breakers do not decelerate falling prices (or returns) and reduce volatility. Table 3 shows that the estimated $\gamma_{\text {OIB.VOL,2 }}$ and $\gamma_{\text {OIB.TRD,2 }}$ in the models, respectively, for OIB.VOL and OIB.TRD are positive and statistically significant. This indicates that, consistent with the first null hypothesis, circuit breakers do not reduce order imbalance in volume and in trades. Table 4 shows that the estimated $\gamma_{\mathrm{VOLUME}, 2}$ and $\gamma_{\mathrm{NTRADE}, 2}$ in the models, respectively, for VOLUME and NTRADE are positive and statistically significant at the 0.01 and 0.05 levels. This suggests that, contrary to the first null hypothesis, circuit breakers do increase trading activities in volume and trades.

Overall, the evidence suggests that circuit breakers have no "cooling effect" in decelerating falling prices (or returns), or reducing market volatility and order imbalance. However, circuit breakers are associated with increased trading activities in volume and trades.

\subsection{Liquidity}

We now examine the impacts of circuit breakers on liquidity. We first examine how bid-ask spreads in price and quote imbalances ${ }^{32}$ in volume are interconnected with other variables of current trade and quote information and then test the second null hypothesis that circuit breakers have no impact on liquidity (spread and depth).

To capture the interconnections among the market microstructure variables, we estimate Lasso IV models using RSPREAD1, RSPREAD2, RSPREAD3, QIM1, QIM2, and QIM3 as dependent variables.

As shown in Table 5, RSPREAD1 is significantly correlated with endogenous variables RCSI300, RV.STK, VOLUME, NTRADE, RSPREAD2, and RSPREAD3 except QIM1,

\footnotetext{
${ }^{32}$ Sometimes they are referred to as "market sides imbalances."
} 
QIM2, and QIM3. Similarly, RSPREAD2 and RSPREAD3 are significantly correlated with these endogenous variables except QIM1, QIM2, and QIM3. As shown Table 6, QIM1 is significantly correlated with endogenous variables RCSI300, RV.STK, VOLUME, NTRADE, QIM2, and QIM3 except RSPREAD1, RSPREAD2, and RSPREAD3. But QIM2 is only significantly correlated with RCSI300, QIM1, and QIM3, while QIM3 is only significantly correlated with RCSI300, QIM1, and QIM2.

From the above observations, we note that all three best bid-ask spreads in price are significantly correlated with the CSI 300 Index return and trading activities in volume and trades. All three best bid-ask spreads in price are significantly correlated among themselves. All three quote imbalances in volume are significantly correlated with the CSI 300 Index return but only the first best quote imbalance in volume is significantly correlated the CSI 300 Index return, market volatility, and trading activities in volume and trades. All three quote imbalances in volume are significantly correlated among themselves as well. This implies that the market index return and trading activities in volume and trades are the major drivers behind liquidity.

(Please insert Tables 5, 6 about here)

To test the second null hypothesis that circuit breakers have no impact on liquidity measured by spreads and quote imbalances, we use the Lasso IV models with RSPREAD1, RSPREAD2, RSPREAD3, QIM1, QIM2, and QIM3 as dependent variables. The coefficient $\gamma_{i, 2}$ for independent variable CIRCUIT measures the change in liquidity when circuit breakers are imposed. Under the second null hypothesis , $\gamma_{R S P R E A D 1,2}, \gamma_{R S P R E A D 2,2}, \gamma_{R S P R E A D 3,2}$, $\gamma_{Q I M 1,2}, \gamma_{Q I M 2,2}$, and $\gamma_{Q I M 3,2}$ should be zero.

Table 5 shows that the estimated $\gamma_{\mathrm{RSPREAD} 1,2}, \gamma_{\mathrm{RSPREAD} 2,2}$, and $\gamma_{\mathrm{RSPREAD} 3,2}$ for all three bid-ask spreads are statistically insignificant. Table 6 shows that the estimated $\gamma_{\text {QIM1,2 }}$, $\gamma_{\text {QIM2,2 }}$, and $\gamma_{\text {QIM3,2 }}$ for all three quote imbalances are statistically insignificant. These findings indicate that, except for the magnet effect on liquidity observed when the CSI 300 Index return falls towards the $-5 \%$ (or $-7 \%$ ) threshold (discussed in section 4.6), we do not observe significant changes in liquidity when the circuit breakers are imposed.

\subsection{Sizes of Trades}

To test the third null hypothesis that circuit breakers have no impact on sizes of trades in terms of trading volume and the number of trades, we estimate Lasso IV models using 
VOL.SML, VOL.MID, VOL.LRG, TRD.SML, TRD.MID, and TRD.LRG as dependent variables. The coefficient $\gamma_{i, 2}$ for independent variable CIRCUIT measures the change in sizes of trades when circuit breakers are imposed. Under the third null hypothesis, $\gamma_{V O L . S M L, 2}$, $\gamma_{V O L . M I D, 2}, \gamma_{V O L . L R G, 2}, \gamma_{T R D . S M L, 2}, \gamma_{T R D . M I D, 2}$, and $\gamma_{T R D . L R G, 2}$ should be zero.

As shown in Table 7, consistent with the third null hypothesis, the estimated $\gamma_{\mathrm{VOL} . S M L, 2}$ in the model for VOL.SML is statistically insignificant. But, inconsistent with the third null hypothesis, the estimated $\gamma_{\text {VOL.MID,2 }}$ and $\gamma_{\text {VOL.LRG,2 }}$ in the models, respectively, for VOL.MID and VOL.LRG are negative and statistically significant. This implies that circuit breakers have negative impacts on trading volume for mid-sized and large-sized trades but not on that for small-sized trades. With circuit breakers, trading volume for small-sized trades falls least (do not change) while that for large-sized trades falls most. As shown in Table 8, inconsistent with the third null hypothesis, the estimated $\gamma_{\text {TRD.SML , } 2}, \gamma_{\text {TRD.MID,2 }}$, and $\gamma_{\text {TRD.LRG,2 }}$ in the models, respectively, for TRD.MID TRD.MID, and TRD.LRG are negative and statistically significant. This implies that circuit breakers have negative impacts on the numbers of trades for all trades of various sizes. With circuit breakers, the number of small-sized trades falls most while the number of large-sized trades falls least.

(Please insert Tables 78 about here)

From the above observations, we note that the circuit breakers indeed affect sizes of trades in terms of trading volume and the number of trades. Combining the above findings on both trading volume and the number of trades, we find that, with circuit breakers, small-sized trades fall most but their volumes do not change while large-sized trades falls least but their volumes fall most.

\subsection{The Magnet Effect}

To test the fourth null hypothesis of no magnet effect on stock returns, we use the Lasso IV model with RCSI300 as the dependent variable. In the model, the coefficients $\delta_{\mathrm{RCSI} 300,1}$ and $\delta_{\mathrm{RCSI} 300,2}$ measure the net magnet effects of GAP5 and GAP $7_{t}$, respectively, on RCSI300 when the circuit breakers are imposed. Under the fourth null hypothesis of no magnet effect, the coefficients $\delta_{\mathrm{RCSI} 300,1}$ and $\delta_{\mathrm{RCSI} 300,2}$ should be greater than or equal to zero.

Table 2 shows that the estimated $\delta_{\mathrm{RCSI} 300,1}$ and $\delta_{\mathrm{RCSI} 300,2}$ are negative and statistically significant. This implies that, contrary to the fourth null hypothesis of no magnet effect, 
when the CSI 300 Index return falls towards the $-5 \%$ (or $-7 \%$ ) threshold, the stock market index falls further. This is a clear evidence for the magnet effect on stock returns.

We find that the magnet effect also affects other market microstructure variables when the CSI 300 Index return falls towards the $-5 \%$ (or $-7 \%$ ) threshold.

First, the magnet effect affects order imbalance in volume and trades. Table 3 shows that the estimated $\delta_{\text {OIB.VOL }, 1}, \delta_{\text {OIB.VOL }, 2}, \delta_{\text {OIB.TRD,1 }}$, and $\delta_{\text {OIB.TRD, } 2}$ are all positive and statistically significant. This implies that when the CSI 300 Index return falls towards the $-5 \%$ (or $-7 \%$ ) threshold, order imbalances in both volume and trades rise further.

Second, trading activities are also affected by the magnet effect. Table 4 shows that the estimated $\delta_{\mathrm{VOLUME}, 1}, \delta_{\mathrm{VOLUMe}, 2}, \delta_{\mathrm{NTRADE}, 1}$, and $\delta_{\mathrm{NTRADE}, 2}$ are all positive and statistically significant. This implies that when the CSI 300 Index return falls towards the $-5 \%$ (or $-7 \%$ ) threshold, overall trading activities in volume and trades rise further.

Third, the magnet effect does impact quote imbalances although the presence of circuit breakers does not affect quote imbalances as reported earlier. Table 6 shows that the estimated $\delta_{\mathrm{QIM} 1,1}$ and $\delta_{\mathrm{QIM} 1,2}$ are all negative and statistically significant while the estimated $\delta_{\mathrm{QIM} 2,1}, \delta_{\mathrm{QIM} 2,2}, \delta_{\mathrm{QIM} 3,1}$, and $\delta_{\mathrm{QIM} 3,2}$ are all positive and statistically significant. A negative (positive) change in the quote imbalance implies a lower (higher) bid volume relative to a higher (lower) ask volume. The above findings imply that when the CSI 300 Index return falls towards the $-5 \%$ (or $-7 \%$ ) threshold, the first best quote imbalance is skewed further by a higher ask volume while the second and third best quote imbalances are skewed further by a higher bid volume. Figure 17 (a) shows that, among three measures of quote imbalances, only the empirical density function of the first best quote imbalance (QIM1) has a long left tail. This is because, the empirical density function of the first best ask volume (ASKVOL1) has a much longer right tail relative to that of the first best bid volume (BIDVOL1), as shown in Figure 17 (b); whereas the second and third best bid and ask volumes (BIDVOL2, ASKVOL2, BIDVOL3, and ASKVOL3) have lesser imbalances, as shown in Figure 17 (c) and $(\mathrm{d})$.

(Please insert Figure 17 about here)

Fourth, the magnet effect is pronounced in trading activities of various sized trades (small-, mid- and large-sized trades). Table 7 shows that the estimated $\delta_{\text {VOL.SML }, 1}, \delta_{\text {VOL.SML }, 2}$, $\delta_{\text {VOL.MID }, 1}, \delta_{\text {VOL.SML }, 2}, \delta_{\text {VOL.LRG }, 1}$, and $\delta_{\text {VOL.LRG }, 2}$ are all negative and statistically significant while $\beta_{\text {VOL.SML }, 3}, \beta_{\text {VOL.MID }, 3}$, and $\beta_{\text {VOL.LRG }, 3}$ are all positive and statistically significant. This implies that when the CSI 300 Index return falls towards the $-5 \%$ (or $-7 \%$ ) threshold, the 
volumes of various sized trades (small-, mid-, and large-sized trades) fall marginally while keeping up the trend of the overall volume. Similarly, Table 8 shows that the estimated

$\delta_{\mathrm{TRD} . \mathrm{SML}, 1}, \delta_{\mathrm{TRD} . \mathrm{SML}, 2}, \delta_{\mathrm{TRD} . \mathrm{MID}, 1}, \delta_{\mathrm{TRD} . \mathrm{SML}, 2}, \delta_{\mathrm{TRD} . \mathrm{LRG}, 1}$, and $\delta_{\mathrm{TRD} . \mathrm{LRG}, 2}$ are all negative and statistically significant while $\beta_{\text {TRD.SML,4 }}, \beta_{\text {TRD.MID,4 }}$, and $\beta_{\text {TRD.LRG,4 }}$ are all positive and statistically significant. This implies that when the CSI 300 Index return falls towards the $-5 \%$ (or - $7 \%$ ) threshold, the numbers of trades of various sized trades (small-, mid-, and large-sized trades) fall marginally while keeping up the trend of the overall number of trades.

\section{Conclusions}

In this paper, we study the impacts of market-wide circuit breakers on the key market microstructure variables based on high frequency intraday data. In particular, we are interested in evaluating if circuit breakers have any "cooling effect" on stock returns, market volatility, order imbalance, and trading activities in volume and trades, if circuit breakers affect liquidity, if circuit breakers affect sizes of trades, and, finally, if circuit breakers have any magnet effect on stock returns and other market microstructure variables. The stock market's saga in China during January 2016 provides an ideal environment for studying how circuit breakers affect market microstructure.

This paper has three innovations in research methodology. First, we use Lasso IV models to capture the interconnections among, therefore the endogeneity of, market microstructure variables and identify a pool of a priori valid instrumental variables for an IV estimation based on the literature on both econometrics and market microstructure. Second, we implement Lasso IV estimation to select, from the pool, strong instrumental variables. Third, by using a test for over-identification, we restrict chosen instrumental variables to those with more lags that are less likely to be endogenous due to inherent intertemporal correlations. This test is the joint significant test of Lasso estimation of the auxiliary regression of Lasso IV residuals on instrumental variables and control variables. This test for Lasso IV estimation is in the same spirit of the Sagan test for IV estimation.

Based on the estimation results, we find that circuit breakers have no "cooling effect" in decelerating falling prices (or returns) and reducing market volatility and order imbalance, but they have limited "cooling effect" in increasing trading volume and the number of trades. The presence of circuit breakers has little impact on bid-ask spreads but does causes trades of various sizes to fall in both volume and the number of trades. We also find that circuit breakers induce significant magnet effects on stock returns, order imbalance, quote imbalance, 
and trades of various sizes. 


\section{References}

[1] Abad, D. and Pascal, R., 2007. On the magnet effect of price limits. European Financial Management, 13, 833-852.

[2] Ackert, L.F., Church, B. and Jayaraman, N., 2001. An experimental study of circuit breakers: The effects of mandated market closures and temporary halts on market behavior. Journal of Financial Markets, 4, 185-208.

[3] Ackert, L.F., Church, B.K. and Jayaraman, N., 2005. Circuit breakers with uncertainty about the presence of informed agents: I know what you know... I think. Financial markets, Institutions and Instruments, 14 (3), 135-167.

[4] Andersen, T. G. and Bollerslev, T., 1998. Answering the skeptics: Yes, standard volatility models do provide accurate forecasts. International Economic Review, 39, 885-905.

[5] Andersen, T. G., Bollerslev, T., Diebold, F. X., and Ebens, H., 2001. The distribution of realized stock return volatility. Journal of Financial Economics, 61, 43-76.

[6] Belloni, A., Chen, D., Chernozhukov, V., and Hansen, C., 2012. Sparse models and methods for optimal instruments with an application to eminent domain, Econometrica, 80, 2369-2429.

[7] Belloni, A., Chernozhukov, V. and Hansen, C., 2014. Inference on treatment effects after selection among high-dimensional controls, Review of Economic Studies, 81, 608-650.

[8] Chen, G., Rui, O. and Wang, S., 2005. The effectiveness of price limits and stock characteristics: Evidence from the Shanghai and Shenzhen Stock Exchanges. Review of Quantitative Finance and Accounting 25(2), 159-182.

[9] Chen, H., Petukhov H. and Wang, J, 2017. The dark side of circuit breakers, Working Paper, MIT.

[10] Chernozhukov, V., Chetverikov, D. and Kato, K., 2013. Gaussian approximations and multiplier bootstrap for maxima of sums of high-dimensional random vectors, Annals of Statistics, 41, 2786-2819.

[11] Chernozhukov, V., Hansen, C. and Spindler, M., 2015. Post-selection and postregularization inference in linear models with many controls and instruments, American Economic Review, 105, 486-490. 
[12] Cho, D.D., Russell, J., Tiao, G.C. and Tsay, R., 2003. The magnet effect of price limits: Evidence from high-frequency data on Taiwan Stock Exchange. Journal of Empirical Finance, 10, 133-168.

[13] Corwin, S. A., and Lipson, M. L., 2000. Order flow and liquidity around NYSE trading halts. Journal of Finance, 55(4), 1771-1801.

[14] Dhaliwal, D., and Li, O. Z., 2006. Investor tax heterogeneity and ex-dividend day trading volume. Journal of Finance, 61, 463-490.

[15] Du, Y.D., Liu, Q., and Rhee, G.S., 2009. An analysis of the magnet effect under price limits. International Review of Finance, 9, 83-110.

[16] Fair, R. C. 1970. The estimation of simultaneous equation models with lagged endogenous variables and first order serially correlated errors, Econometrica, 38 (3), 507-516.

[17] George, T. J. and Hwang, C. 1995. Transitory price changes and price-limit rules: Evidence from the Tokyo Stock Exchange, Journal of Financial and Quantitative Analysis, 30(2), 313-327.

[18] Gerety, M.S. and Mulherin, J.H., 1992. Trading halts and market activity: An analysis of volume at the open and the close. Journal of Finance, 47, 1765-1784.

[19] Goldstein, M.A. and Kavajecz, K.A., 2004. Trading strategies during circuit breakers and extreme market movements. Journal of Financial Markets, 7, 301-333.

[20] Gomber, P., Clapham, B., Haferkorn, M., Panz, S. and Jentsch, P., 2016. Circuit breakers-A survey among international trading venues. World Federation of Exchanges.

[21] Greenwald, B.C. and Stein, J.C., 1991. Transactional risk, market crashes, and the role of circuit breakers. Journal of Business, 64, 443-462.

[22] Grossman, S. J. and Miller, H.M., 1988. Liquidity and market structure, Journal of Finance, 43(3), Papers and Proceedings of the Forty-Seventh Annual Meeting of the American Finance Association, Chicago, Illinois, December 28-30, 1987, 617-633.

[23] Hao, X. 2016. The magnet effect of market-wide circuit breaker: Evidence from the Chinese stock market, Working Paper, School of Economics, Nankai University. 
[24] Harris, L., 1998. Circuit breakers and p rogram trading limits: What have we learned? In Litan, Robert E. and Anthony M Santomero (eds.), Brookings-Wharton Papers on Financial Services, Washington, D.C. : Brooking Institution Press, 1998.

[25] Hautsch, N., and Horvath, A., 2019. How effective are trading pauses?, Journal of Financial Economics, 131(2), 378-403.

[26] Hsieh, P.H., Kim, Y.H. and Yang, J.J., 2009. The magnet effect of price limits: A logit approach. Journal of Empirical Finance, 16, 831-837.

[27] Kim, K. A. and S. G. Rhee, 1997. Price limit performance from the Tokyo Stock Exchange, Journal of Finance 52, 885-901.

[28] Kim, K. A., Liu, H. and Yang, J. J., 2013. Reconsidering price limit effectiveness. Journal of Financial Research, 36(4), 493-571.

[29] Kim, Y. H. and Yang, J. J., 2004. What makes circuit breakers attractive to financial markets? A survey. Financial Markets, Institutions \& Instruments, 13, 109-146.

[30] Koski, J. L., and Michaely, R., 2000. Prices, liquidity and the information content of trades. Review of Financial Studies, 13, 659-696.

[31] Kuhn, B. A., Kuserk, G. J. and Locke, P., 1991. Do circuit breakers moderate volatility? Evidence from October 1989. The Review of Futures Markets, 10, 136-175.

[32] Lauterbach, B., and Ben-Zion, U. 1993. Stock market crashes and the performance of circuit breakers: Empirical evidence. Journal of Finance, 48(5), 1909-1925.

[33] Lee, B., Li, W., Wang, S., 2010. The dynamics of institutional and individual trading on the Stock Exchange of Shanghai. Pacific-Basin Finance Journal, 18(1), 116-137.

[34] Lee, C. M. C., and Ready, M. J., 1991. Inferring trade direction from intraday data. Journal of Finance, 46(2), 733-746.

[35] Lee, C. M. C., Ready, M. J., and Seguin, P. J., 1994. Volume, Volatility, and New York Stock Exchange Trading Halts. Journal of Finance, 49 (1),183-214.

[36] Lin, W., Feng, R. and Li, H., 2015. Regularization methods for high-dimensional instrumental variables regression with an application to genetical genomics, Journal of the American Statistical Association, 110, 270-288. 
[37] Ng, L. and Wu, F., 2007. The trading behavior of institutions and individuals in Chinese equity markets. Journal of Banking and Finance, 31, 2695-2710.

[38] O'Hara, M., 2003. Presidential address: Liquidity and price discovery," Journal of Finance, 58(4), 1335-1354.

[39] O'Hara, M., 2015. High frequency market microstructure, Journal of Financial Economics, 116(2), 257-270.

[40] Sargan, J. D., 1961. The maximum likelihood estimation of economic relationships with autogressive residuals, Econometrica, 29 (3), 414-426.

[41] Subrahmanyam, A., 1994. Circuit breakers and market volatility: A theoretical perspective. Journal of Finance, 49, 237-254.

[42] WFE, 2008. Questionnaire on Circuit Breakers for Q4 2008. World Federation of Exchanges.

[43] WFE, 2016, WFE Survey on Circuit Breakers, World Federation of Exchanges.

[44] Wong, K. M, Kong, X. W. and Li, M. 2016. The magnet effect of circuit breakers and its interactions with price limits, Working Paper, Chu Hai College of Higher Education.

[45] Wong, W. K., Chang, M. C. and Tu, A. H., 2009. Are magnet effects caused by uninformed traders? Evidence from Taiwan Stock Exchange. Pacific-Basin Finance Journal, $17,28-40$.

[46] Wong, W.K., Liu, B. and Zeng, Y., 2009. Can price limits help when the price is falling? Evidence from transactions data on the Shanghai Stock Exchange. China Economic Review, 20, 91-102.

[47] Xu, C. K., 2000. The microstructure of the Chinese stock market. China Economic Review, 11, 79-97.

[48] Yang, X., and Jin, X. 2017. The circuit breakers and magnet effect in Chinese stock market: Evidence from a natural experiment (Wo Guo Gu Piao Shi Chang Rong Duan Ji Zhi De Ci Li Xiao Ying: Ji Yu Zi Ran Shi Yan De Zheng Ju), Journal of Financial Research (Jin Rong Yan Ju in Chinese), No. 9, 161-177. 
Figure 1: The generation of morning opening price in the periodic auction

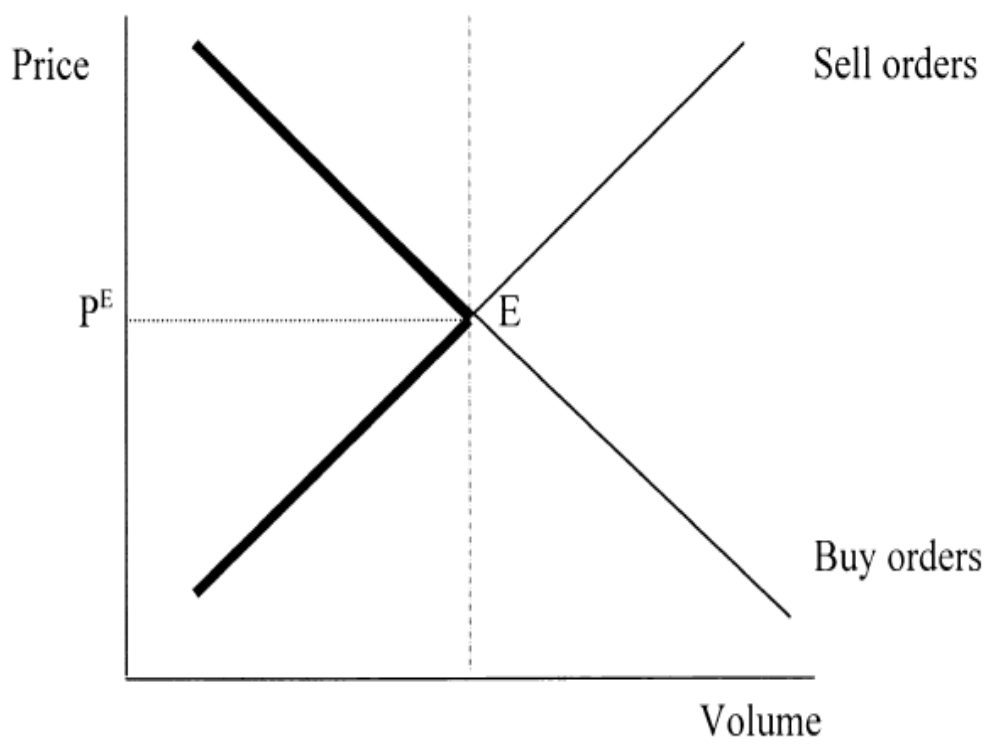

Note: $P^{E}$ is the morning opening price in the periodic auction. $E$ is where the demand and supply schedule intercept and only the prices and lots on the highlighted segments of the two schedules are used to determine $P^{E}$. Source: $\mathrm{Xu}(2000)$ 
Figure 2: The supply schedule in the continuous discriminating auction

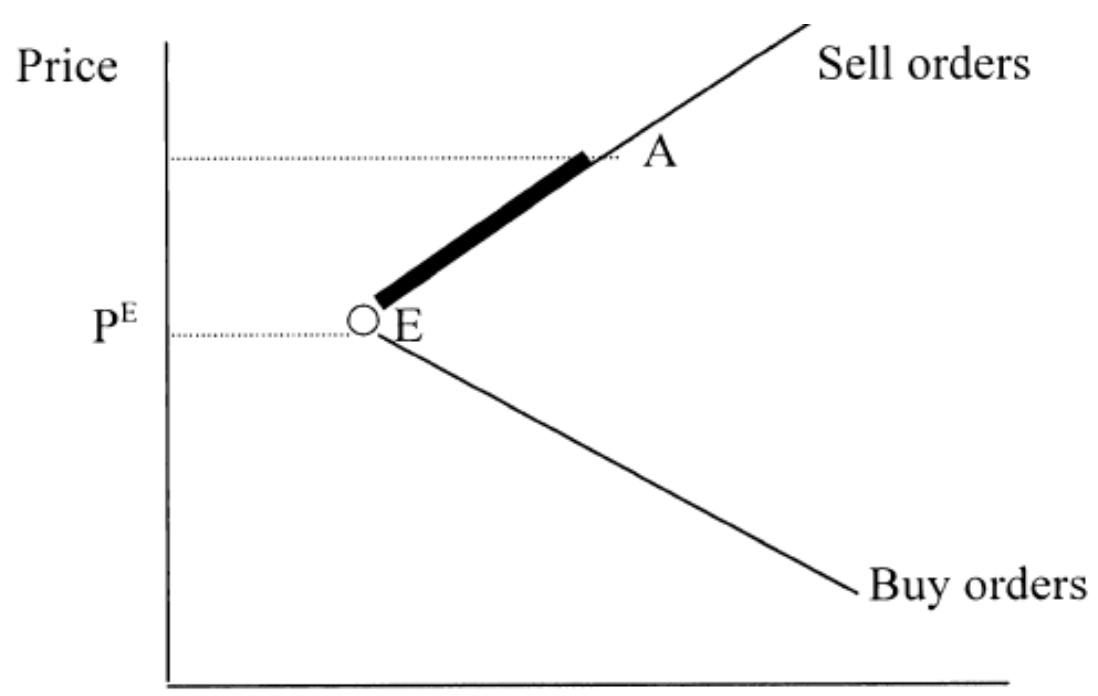

Volume

Note: $P^{E}$ is the price found in the continuous discriminating auction. $E$ is where the demand and supply schedule intercept. In the trading day, the prices and lots on the highlighted segment of the supply schedule are used to determine $P^{E}$. Source: $\mathrm{Xu}(2000)$ 
Figure 3: The demand schedule in the continuous discriminating auction

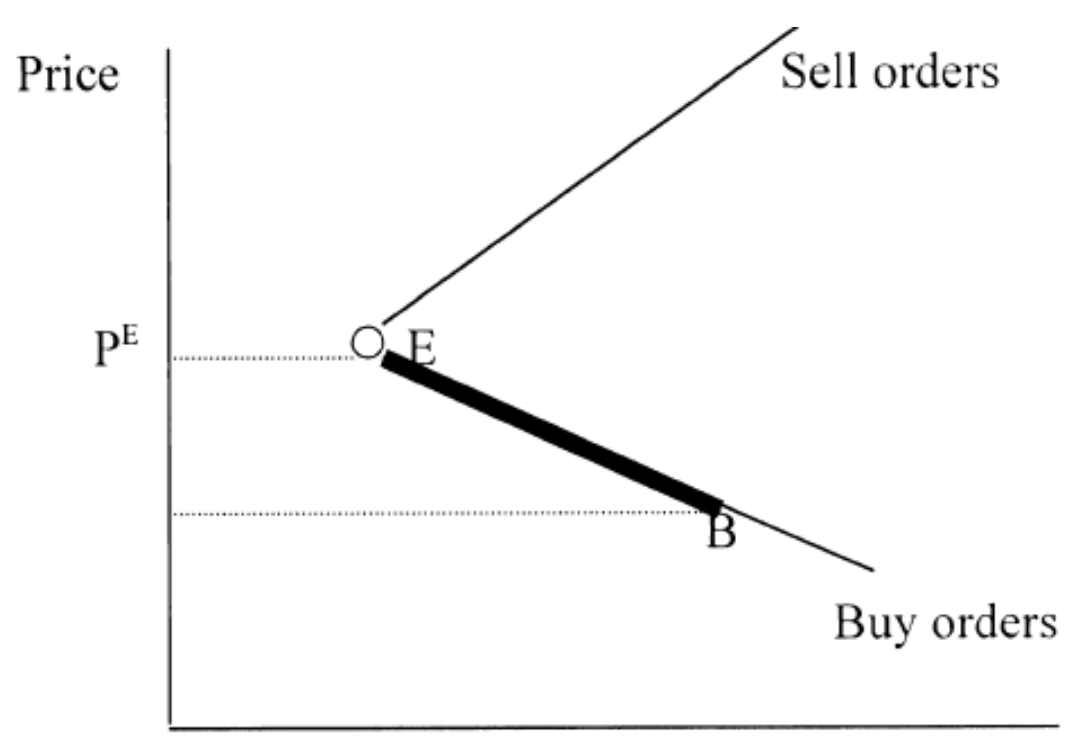

Volume

Note: $P^{E}$ is the price found in the continuous discriminating auction. $E$ is where the demand and supply schedule intercept. In the trading day, the prices and lots on the highlighted segment of the demand schedule are used to determine $P^{E}$. Source: $\mathrm{Xu}(2000)$ 
Figure 4: The China's Manufacturing PMI

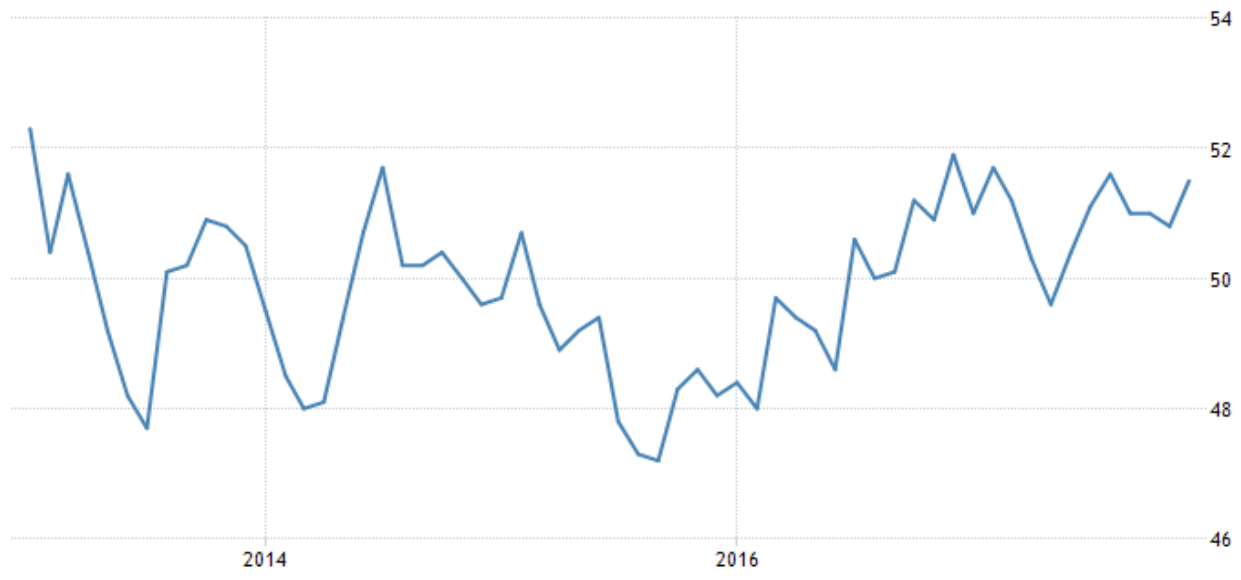

Note: The data are from http://pmi.caixin.com/

Figure 5: The CSI 300 Index Close, Aug. Figure 6: The CSI 300 Index Close, Aug. 18th, 2015

24th, 2015
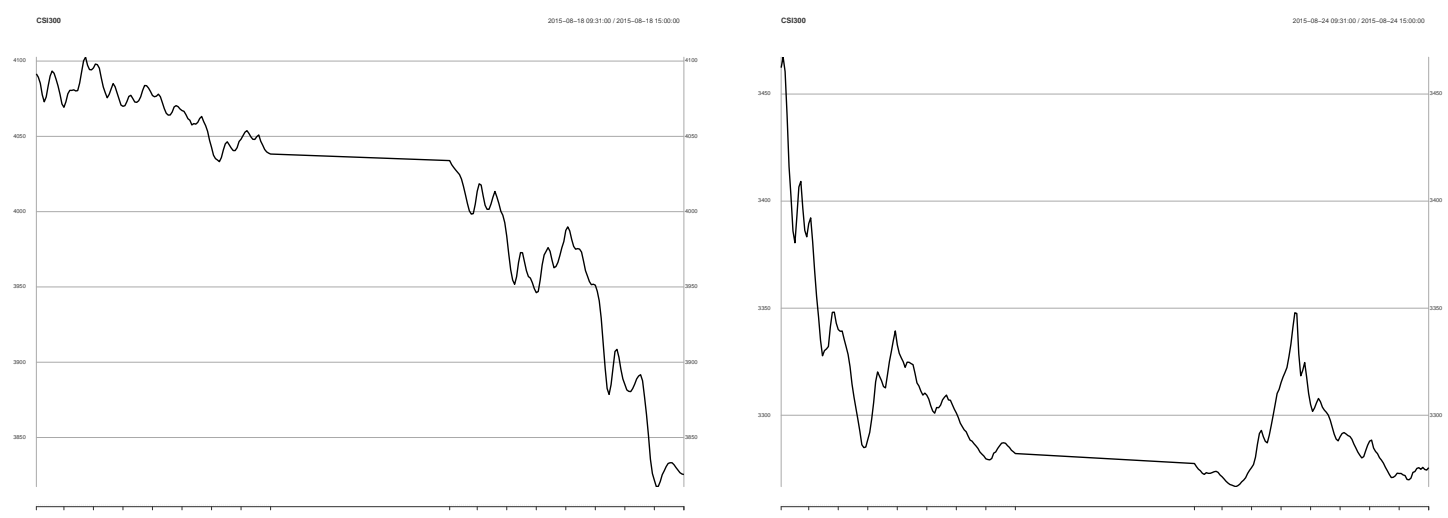

Note: The CSI 300 Index on August 18th, 2015 witnessed a sharp fall. This trading day is included in the control sample prior to the event sample where the circuit breakers were imposed.

Note: The CSI 300 Index on August 24th,

2015 witnessed a sharp fall. This trading day is included in the control sample prior to the event sample where the circuit breakers were imposed. 
Figure 7: The CSI 300 Index Close, Aug. Figure 8: The CSI 300 Index Close, Dec.

25th, 2015

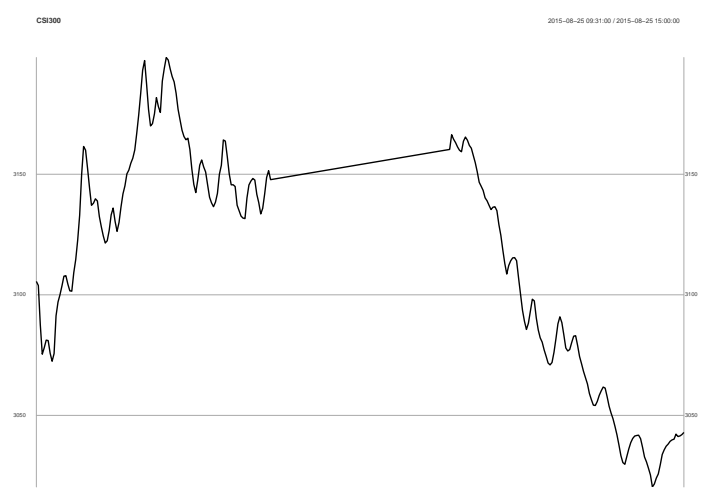

Note: The CSI 300 Index on August 25th 2015 witnessed a sharp fall. This trading day is included in the control sample prior to the event sample where the circuit breakers were imposed. 31st, 2015

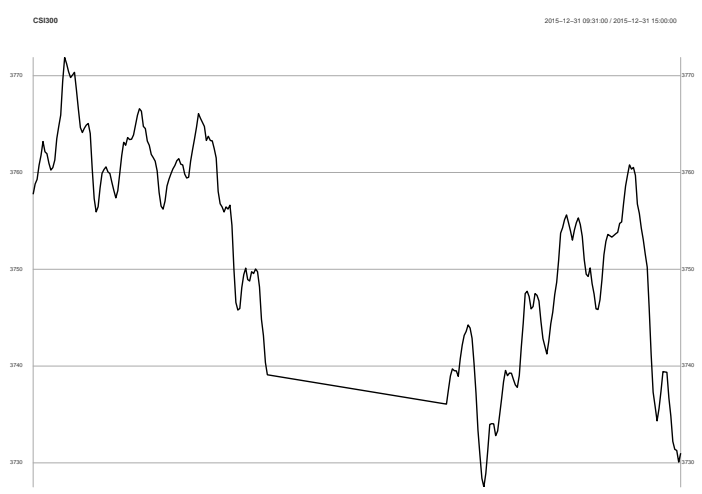

Note: The CSI 300 Index on December 31st, 2015 witnessed a mild fall from 3770 to 3730 . This trading day is not included in either the control sample prior to the event sample where the circuit breakers were imposed or the event sample. The figure is provided to provide the background information.

Figure 9: The CSI 300 Index Close, Jan. Figure 10: The CSI 300 Index Close, Jan.

4th, 2016

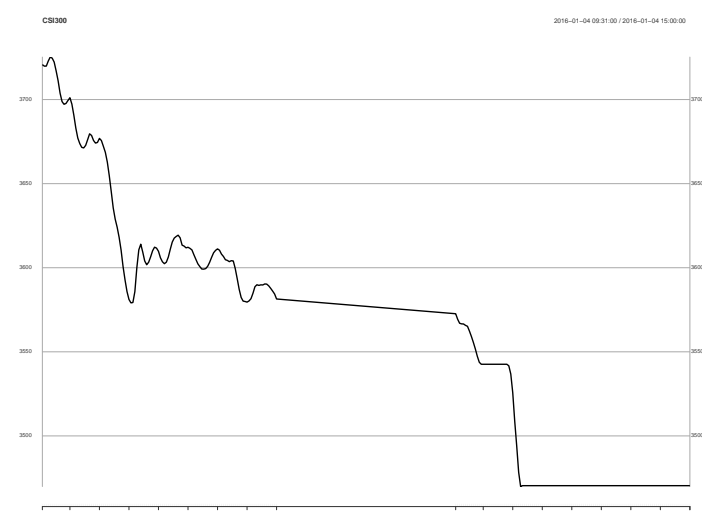

Note: On Monday, January 4th, 2016, the CS 300 Index fell $5 \%$ first at 13:12 and the three exchanges were suspended from trading for 15 minutes based on the newly-implemented circuit breakers rules. After the three exchanges resumed trading at 13:27, the CSI 300 Index fell $7 \%$ again. According to the new rules, the exchanges stopped trading and were closed at 13:43. This trading day is included in the event sample where the circuit breakers were imposed and triggered. 5th, 2016

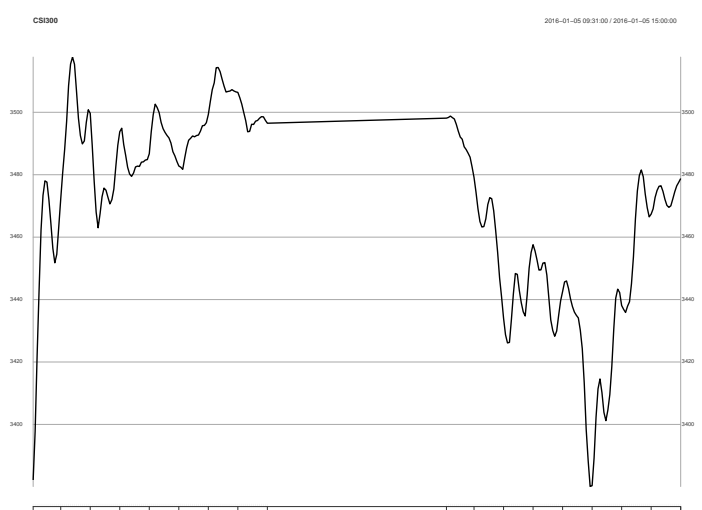

Note: The trading on January 5 th was volatile but the CSI 300 Index did not trigger any circuit breakers. This trading day is included in the event sample where the circuit breakers were imposed but not triggered. 
Figure 11: The CSI 300 Index Close, Jan. Figure 12: The CSI 300 Index Close, Jan. 6th, 2016

7th, 2016
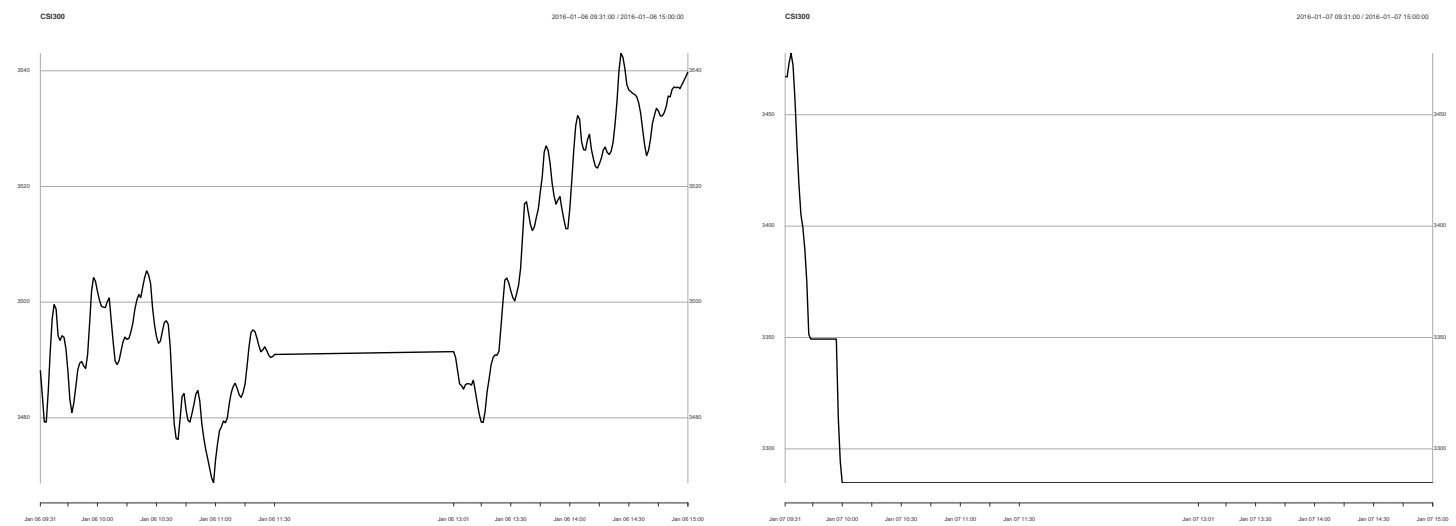

Note: On January 7th, 2016, both the SSE and SZSE opened lower during the first 15 minutes of the trading day. The CSI 300 Index fell $5 \%$ at 9:42, triggering the Level 1 circuit breaker. After a trading halt for 15 minutes, at about 9:57 the CSI 300 Index continued to drop, falling $7 \%$ triggering the Level 2 circuit breaker. Based on the new rules, the three exchanges halted trading and were closed after the markets re-opened only for 15 minutes. This trading day is included in the event sample where the circuit breakers were imposed and triggered.

Figure 13: The CSI 300 Index Close, Jan. Figure 14: The CSI 300 Index Close, Jan. 8th, 2016

11th, 2016
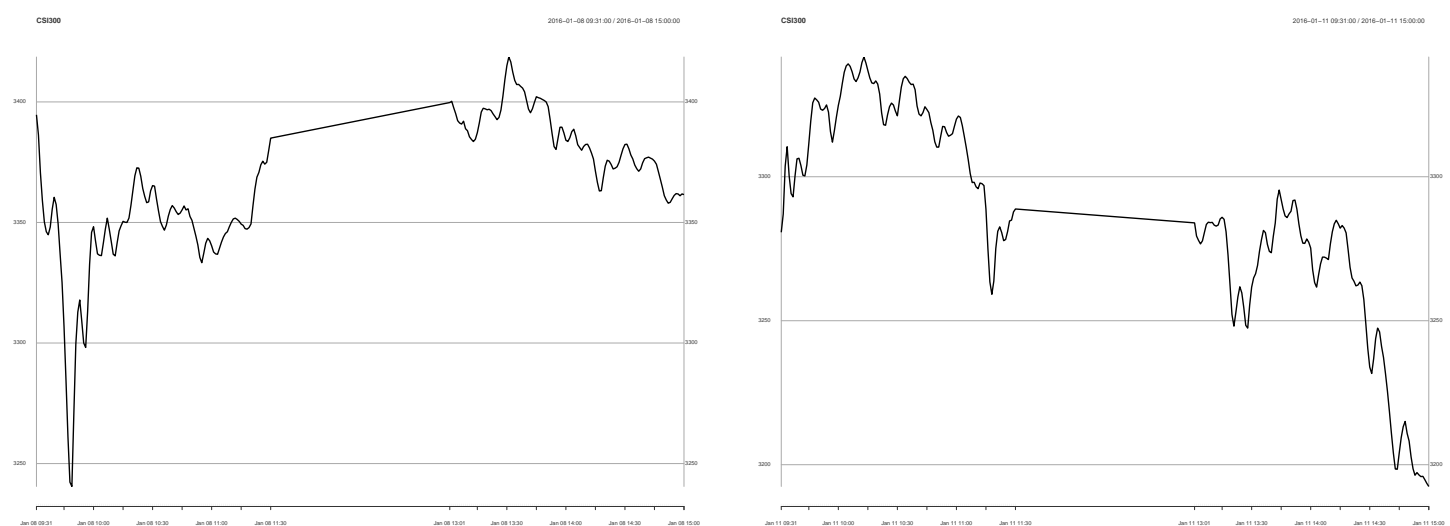

Note: On January 8th, 2016, the CSI 300 Index stabilized approximately around the level of 3550 . This trading day is not included in either the control sample post to the event sample where the circuit breakers were imposed or the event sample. The figure is provided for information. 
Figure 15: The CSI 300 Index Close, Jan. Figure 16: The CSI 300 Index Close, Feb. 26th, 2016 25th, 2016
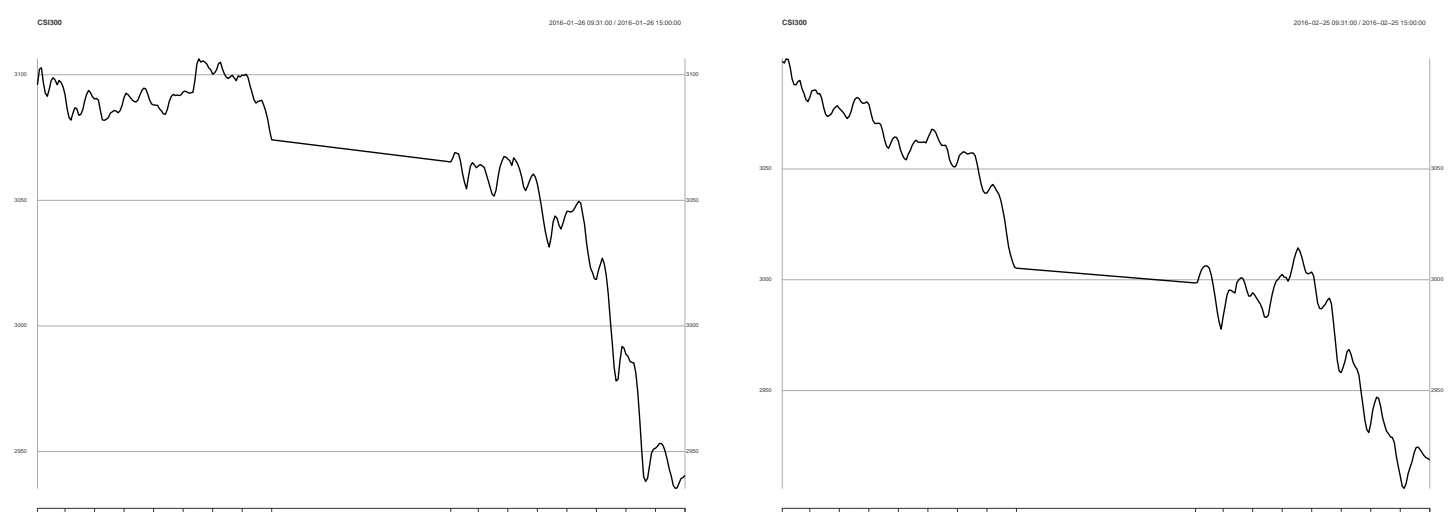

Note: On January 26th, 2016, the CSI 300 Index witnessed a sharp fall. This trading day is included in the control sample post to the event sample where the circuit breakers were imposed.

Note: The CSI 300 Index on February 25th, 2016 witnessed a sharp fall. This trading day is included in the control sample post to the event sample where the circuit breakers were imposed. 
Figure 17: The Empirical Densities of QIM1-QIM3, BIDVOL1-ASKVOL1, BIDVOL2ASKVOL2, and BIDVOL3-ASKVOL3

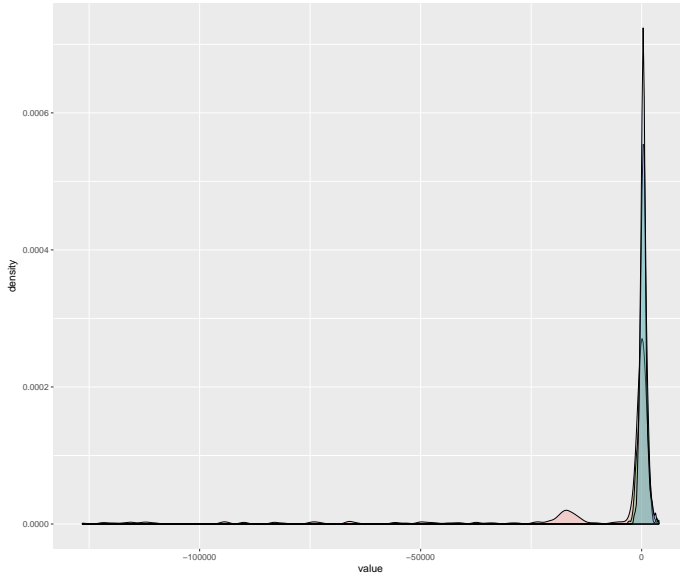

(a) QIM1, QIM2, and QIM3

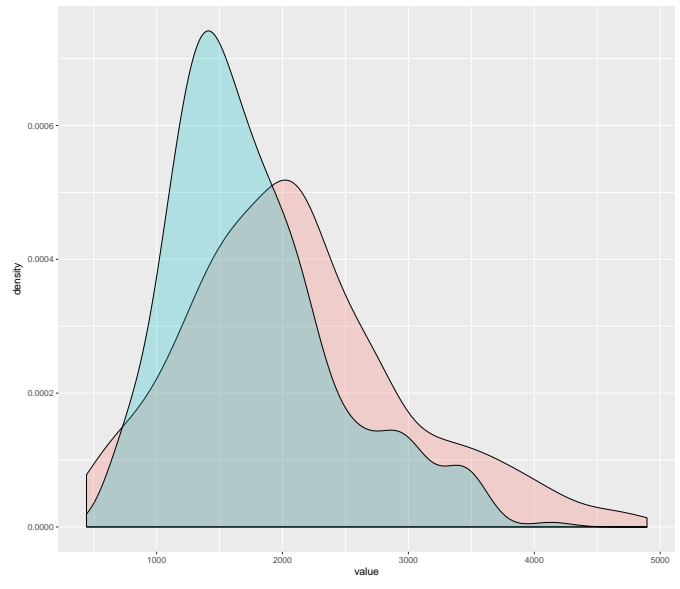

(c) BIDVOL2 and ASKVOL2

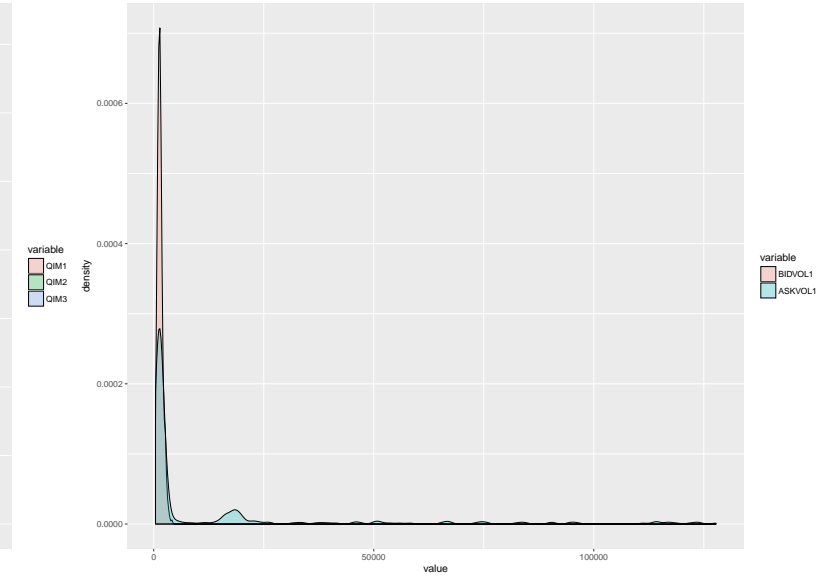

(b) BIDVOL1 and ASKVOL1

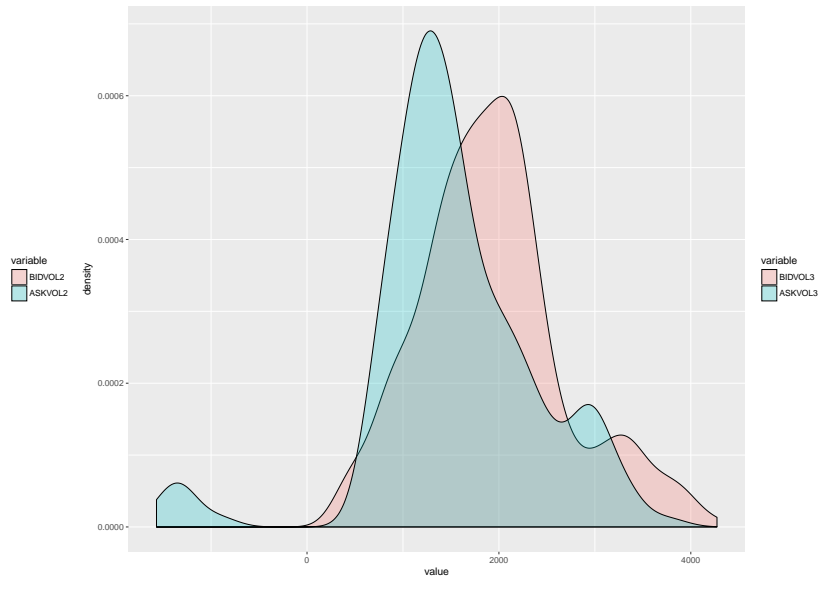

(d) BIDVOL3 and ASKVOL3 
Table 1: Summary Statistics of CSI 300 Index Stocks Daily Trading Activities

\begin{tabular}{rrrrrrrrr}
\hline \hline & \multicolumn{3}{c}{ 4-Jan-16 } & & \multicolumn{3}{c}{ 7-Jan-16 } \\
\hline & \multicolumn{1}{c}{$\begin{array}{c}\text { Return } \\
\%\end{array}$} & $\begin{array}{c}\text { Volume } \\
\text { mil }\end{array}$ & $\begin{array}{c}\text { Value } \\
\text { mil, RMB }\end{array}$ & No. of Trades & $\begin{array}{c}\text { Return } \\
\text { Volume }\end{array}$ & $\begin{array}{c}\text { Value } \\
\text { mil }\end{array}$ & No. of Trades RMB & \\
\hline Mean & -8.19 & 40.19 & 507.35 & 21,944 & -8.33 & 15.00 & 158.65 & 6,312 \\
Stdev. & 1.89 & 46.50 & 459.58 & 18,393 & 1.99 & 21.16 & 152.29 & 5,356 \\
Min & -10.00 & 1.56 & 48.10 & 2,673 & -10.00 & 0.43 & 10.94 & 765 \\
$25 \%$ & -9.98 & 13.11 & 209.57 & 9,985 & -9.87 & 3.88 & 63.42 & 2,717 \\
Median & -8.90 & 25.57 & 374.15 & 17,208 & -9.10 & 8.28 & 121.06 & 4,736 \\
$75 \%$ & -6.84 & 47.71 & 668.38 & 27,984 & -7.47 & 18.86 & 198.32 & 8,524 \\
Max & -2.75 & 414.42 & 3587.36 & 138,377 & -1.89 & 188.47 & $1,253.84$ & 35,226 \\
N & & & $6,298,064$ & & & & $1,811,668$ \\
\hline \hline
\end{tabular}

Note: The summary statistics in this table are calculated based on tick-by-tick data for stock returns and trading activities. The stock return of the CSI 300 Index stocks falls rapidly in these two trading days. On January 4th, 2016 (January 7th, 2017), the return of the CSI 300 Index stocks falls 8.19\% (8.33\%) on average. These stocks are highly liquid on these two trading days. On January 4th, 2016 (January 7th, 2017), the mean daily trading volume is 40 million (15 million) shares, the trading value is RMB 507.35 million (RMB 158.65 million), and the trading frequency of 21,944 (6,312) trades. The total number of transactions for our analysis is about 6.3 million and 1.8 million transactions on January 4th and 7th, 2016, respectively. The average exchange rate is RMB 6.5744 per USD in January 2016. 


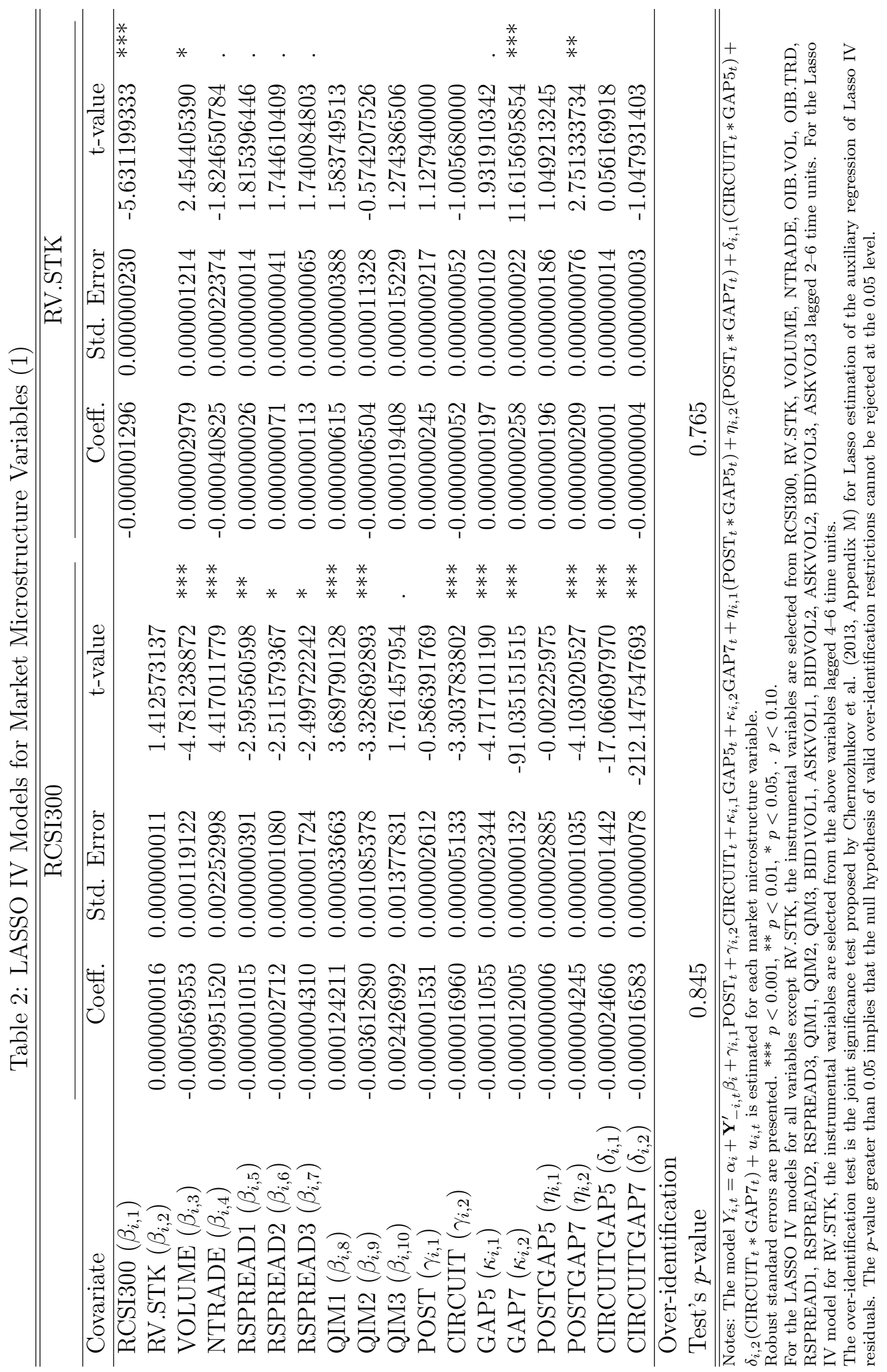




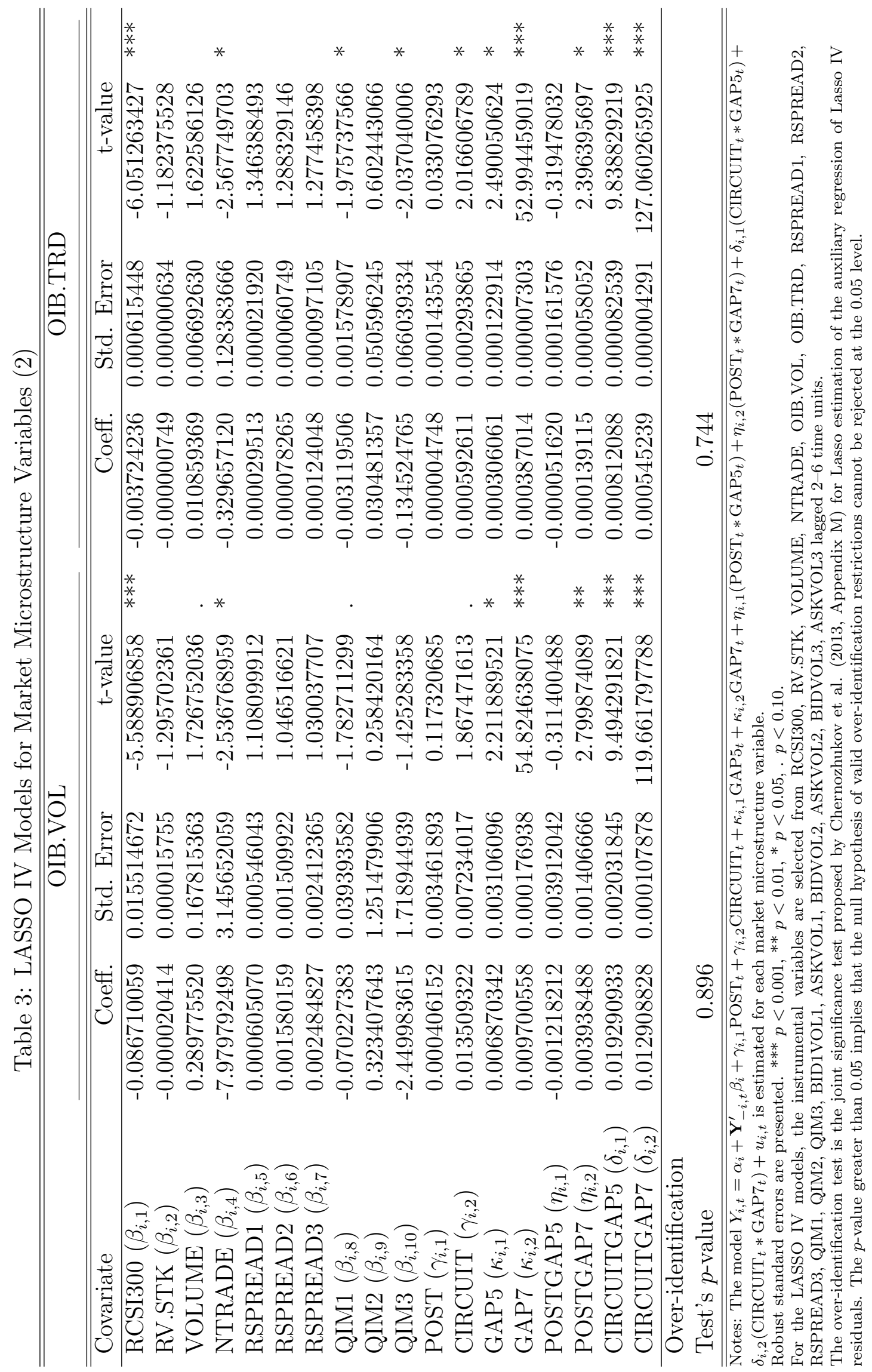




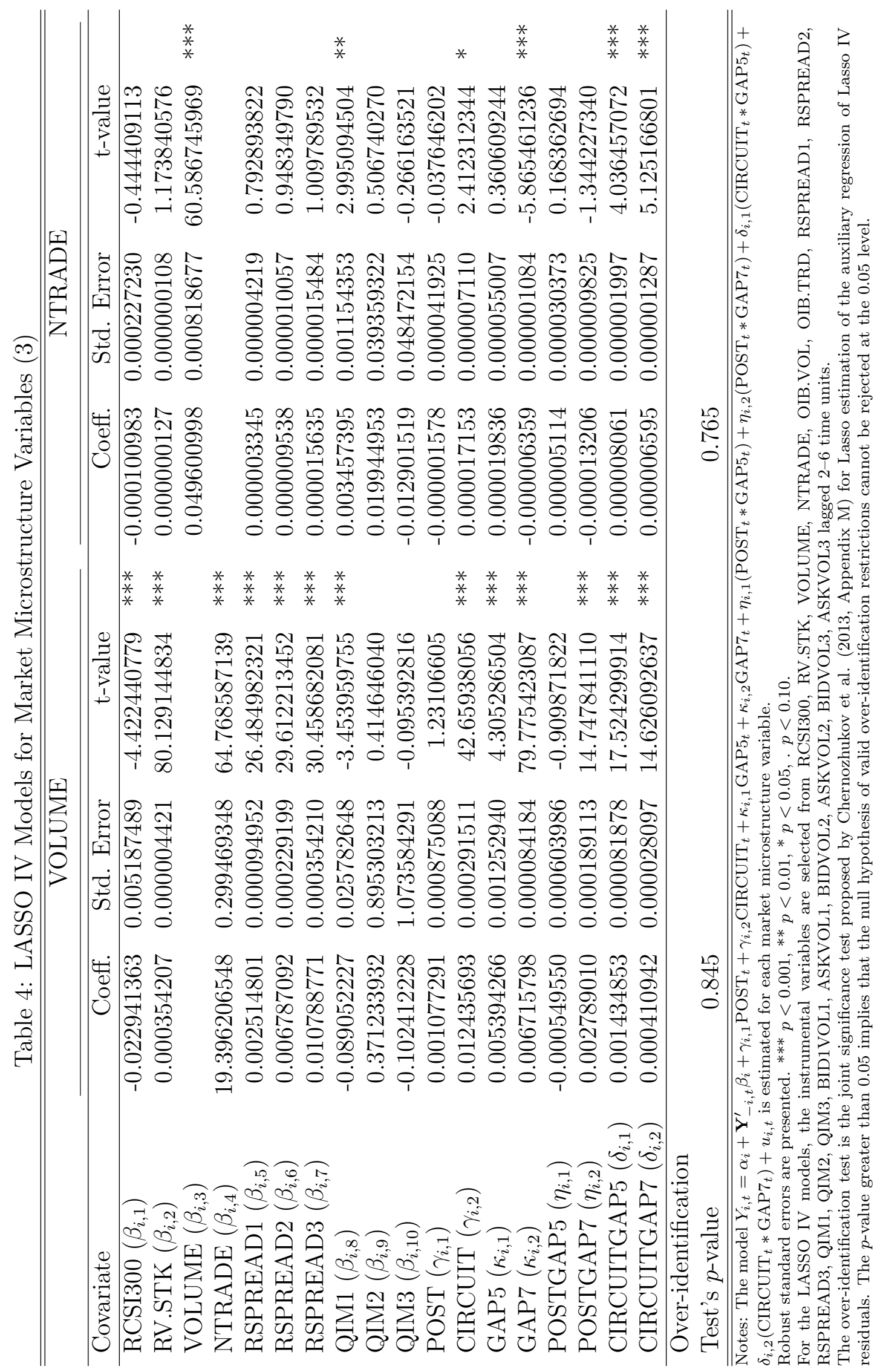




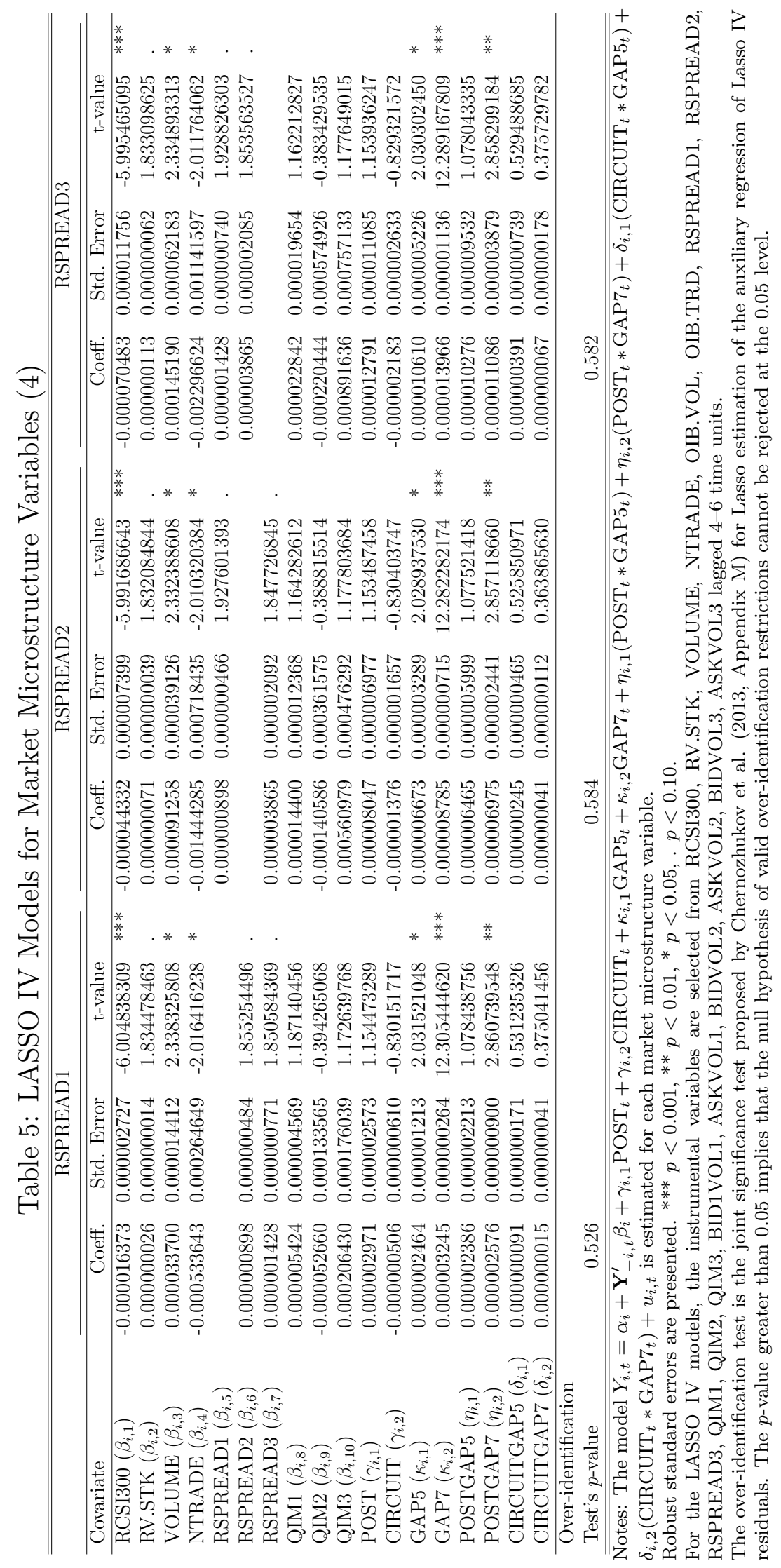




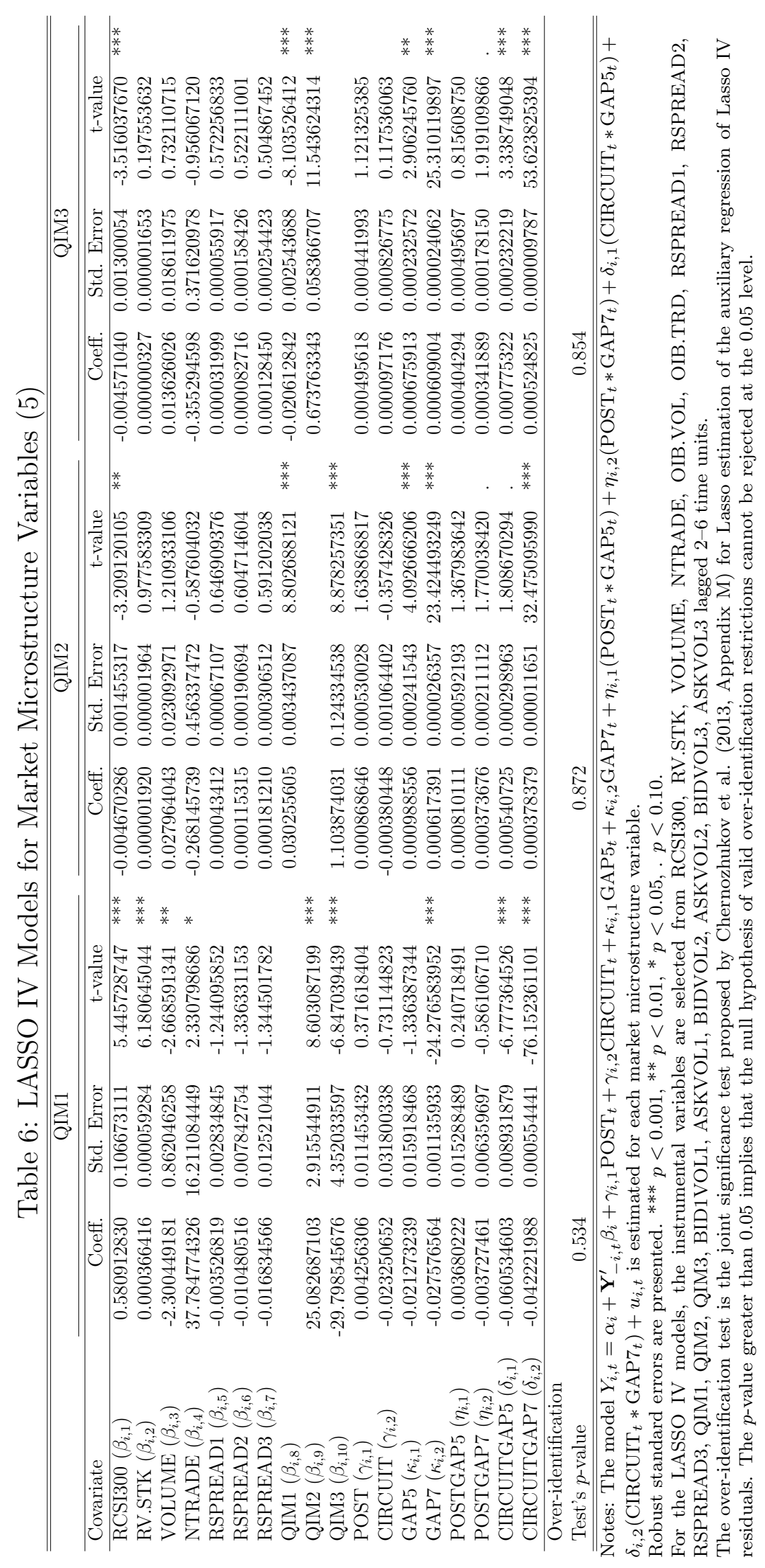




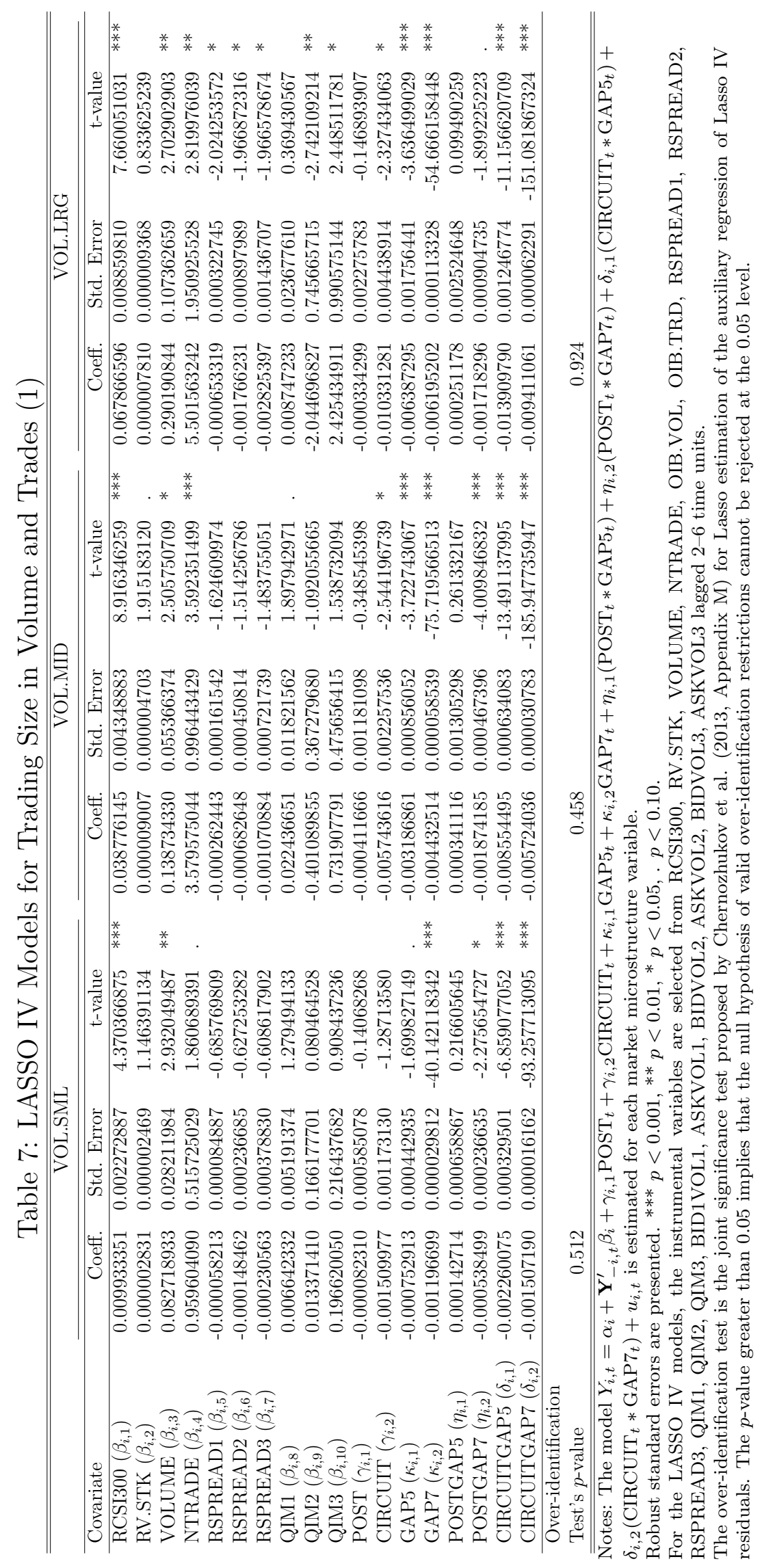




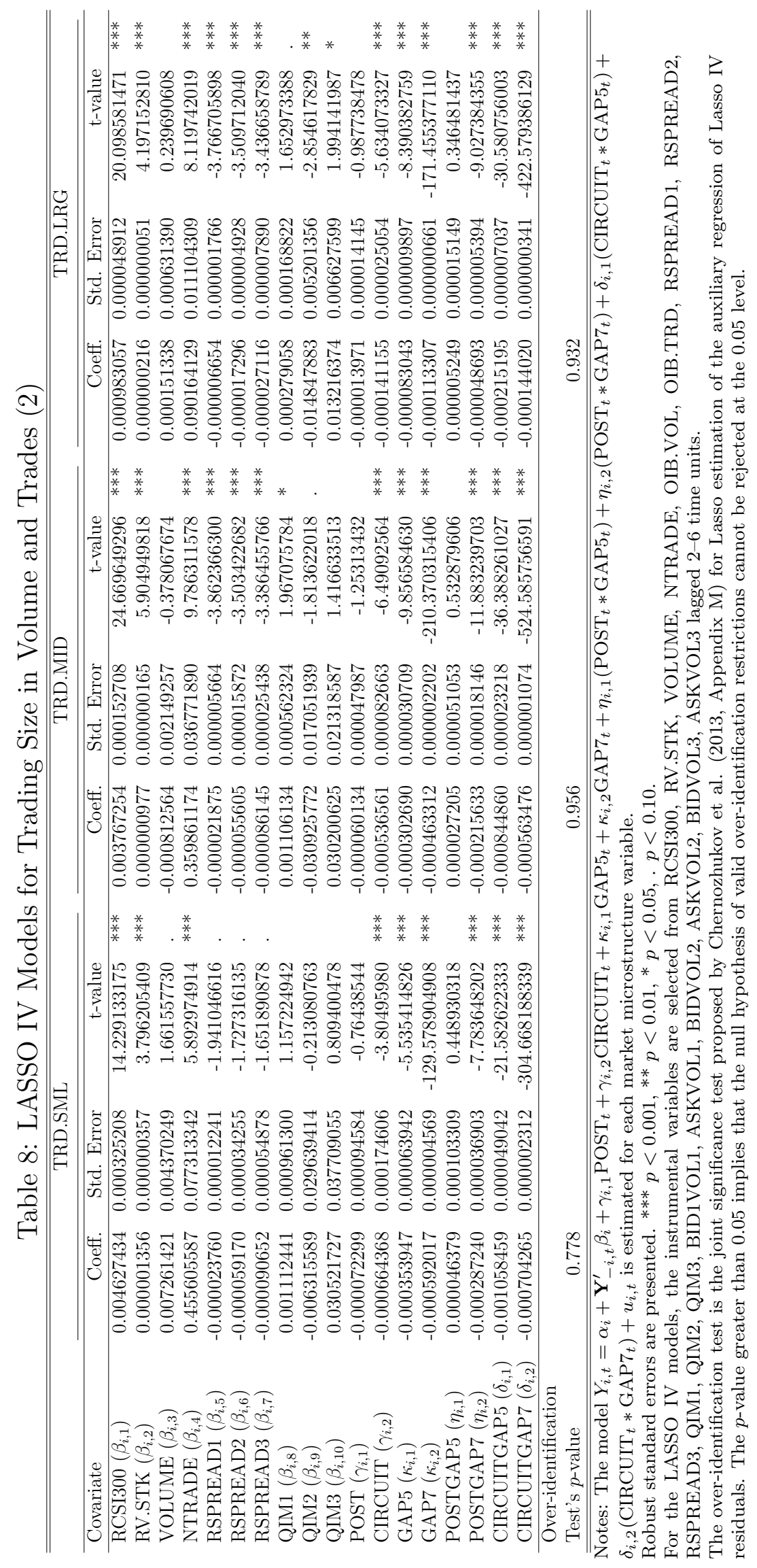




\section{Appendix}

\section{A Variable Definitions}

In this appendix, we define the list of variables analyzed in this research, including both intermediate and final variables used in the analysis. See Table A1.

RCSI300 is the percentage change of, or the return on, the CSI 300 Index at a point in time (e.g., at every 5-minutes) in the current trading day relative to the CSI 300 Index at the corresponding point in time in the previous trading day. This variable serves as a benchmark return of the market index for the circuit breakers.

RV.STK is a measure of the realized volatility calculated in two steps. First, the realized volatility for each stock is calculated with tick-by-tick data for the stock within fixed time intervals based on

$$
\mathrm{RV} . \mathrm{STK}=\sqrt{\sum_{i=1}^{n} r_{i}^{2}},
$$

where $r_{i}$ is the $i$-th tick-by-tick stock return and $n$ is the number of intraday returns in fixed time (e.g., 5-minute) intervals. Then the average of these realized volatility measures for all stocks in the CSI 300 Index is calculated to obtain the average RV.STK for the CSI 300 Index.

The volume of trade, VOLUME, is defined as the average number of shares in round lots (100 shares) traded for all individual stocks.

The number of trades, NTRADE, is defined as the average number of trades for all individual stocks.

OIB.VOL is a measure for order imbalance in volume. The volume of stocks from buys, identified as the trades initiated by buyers, is denoted as VOLBUYS. The volume of stocks from sells, identified as the trades initiated by sellers, is denoted as VOLSELLS. The measure of order imbalance in volume, OIB.VOL, is defined as:

$$
\text { OIB.VOL = VOLBUYS }- \text { VOLSELLS. }
$$

OIB.TRD is a measure of order imbalance in trades. The number of trades from buys, identified as the trades initiated by buyers, is denoted as TRDBUYS. The number of trades from sells, identified as the trades initiated by sellers, is denoted as TRDSELLS. The measure 
of order imbalance in trades, OIB.TRD, is defined as order imbalances in trades:

$$
\text { OIB.TRD }=\text { TRDBUYS }- \text { TRDSELLS }
$$

CIRCUIT is a dummy variable for the circuit breakers. POST is a dummy variable for the post-event sample.

GAP5 measures how close in percentage points the fall of the CSI 300 Index return (RCSI300) is to the $-5 \%$ threshold if the return falls $2 \%$ or more but no more than $5 \%$. Similarly, GAP7 measures how close in percentage points the fall of the CSI 300 Index return (RCSI300) is to the $-7 \%$ threshold if the return falls $4 \%$ or more but no more than $7 \%$. If the CSI 300 Index return is outside the 3 percentage point window for the $-5 \%(-7 \%)$ threshold, GAP5 (GAP7) is assigned zero.

We define the small-, middle-, and large-sized trades following $\mathrm{Ng}$ and $\mathrm{Wu}$ (2007). If the total value of a trade is less than 10,000 RMB, we call this trade a small-sized trade. If the total value of a trade is greater than or equal to 10,000 RMB but less than 50,000 RMB, we call this trade a middle-sized trade or a mid-sized trade. If the total value of a trade is greater than or equal to 50,000 RMB, we call this a large-sized trade. Second, we define the volume measures across small-, middle-, and large-sized trades. VOL.SML, VOL.MID, and VOL.LRG are used to denote the volumes of small-, middle-, and large-sized trades, respectively, while TRD.SML, TRD.MID, and TRD.LRG are used to denote the numbers of small-, middle-, and large-sized trades, respectively.

The ask and bid prices (ASK and BID) are used to calculate the absolute bid-ask spread (SPREAD) and the relative bid-ask spread (RSPREAD) ${ }^{33}$ The absolute bid-ask spread (SPREAD) is calculated by

$$
\mathrm{SPREAD}=\mathrm{ASK}-\mathrm{BID}
$$

SPREAD is the smallest difference between the ask price and the bid price for a stock for which no price limits are in effect. Because along the demand and supply schedules, we are able to select the first closest or best ASK and BID, the second closest or best ASK and BID, and the third closest or best ASK and BID, we name them SPREAD1, SPREAD2,

\footnotetext{
${ }^{33}$ Our intraday data contain the quote data over the 3 -seconds intervals and the transaction data are tick-by-tick in real time. We analyze the intraday data over the 5-minute intervals. Therefore, the bid price, ask price, and absolute bid-ask spread are the averages over the 5-minute intervals.
} 
and SPREAD3, respectively. The relative bid-ask spread (RSPREAD) is calculated by

$$
\text { RSPREAD }=\frac{\text { SPREAD }}{(\mathrm{ASK}+\mathrm{BID}) / 2} .
$$

Depending on the how close ASK and BID are, we name RSPREAD as RSPREAD1, RSPREAD2, and SPREAD3, respectively. We calculate the absolute and relative bid-ask spread for each stock in the CSI 300 Index over fixed time (e.g., 5-minute) intervals and then calculate the average of the absolute and relative bid-ask spreads within each fixed time (e.g., 5-minute) interval for all stocks in the CSI 300 Index.

The bid- and ask-volumes (BIDVOL and ASKVOL) for a stock over fixed time (e.g., 5-minute) intervals are used to calculate the quote imbalance (QIM) for that stock over the same intervals:

$$
\mathrm{QIM}=\mathrm{BIDVOL}-\mathrm{ASKVOL} .
$$

We then calculate the average bid- and ask-volumes (BIDVOL and ASKVOL) and average quote imbalances (QIM) within each fixed time (e.g., 5-minute) interval for all stocks in the CSI 300 Index.

(Please insert Table A1 about here) 
Table A1: List of Definitions and Variables

\begin{tabular}{|c|c|}
\hline Variable Name & Description \\
\hline CSI300 & The CSI 300 Index \\
\hline RCSI300 & The cumulative return on the CSI 300 Index over the trading day, which is compared with the $5 \%$ and $7 \%$ circuit breaker thresholds \\
\hline RV.STK & $\begin{array}{l}\text { Realized volatility for a stock using tick-by-tick intraday data over fixed time (e.g., } 5 \text {-minute) intervals } ; \text { RV.STK }=\sqrt{\sum_{i}^{n} r_{i}^{2}} \\
\text { where } n \text { is the number of tick-by-tick intraday returns on a stock, } r_{i} \text {, over fixed time (e.g., } 5 \text {-minute) intervals }\end{array}$ \\
\hline VOLUME & The average number of shares traded per stock in round lots $(* 100)$ across the stocks in the CSI 300 Index \\
\hline NTRADE & The average number of trades per stock across the stocks in the CSI 300 Index \\
\hline VOLBUYS & The volume of stocks from buys, identified as the trades initiated by buyers \\
\hline VOLSELLS & The volume of stocks from sells, identified as the trades initiated by sellers \\
\hline OIB.VOL & Order imbalance in volume; OIB.VOL = VOLBUYS - VOLSELLS \\
\hline TRDBUYS & The number of trades from buys, identified as the trades initiated by buyers \\
\hline TRDSELLS & The number of trades from sells, identified as the trades initiated by sellers \\
\hline OIB.TRD & Order imbalance in trades; OIB.TRD = TRDBUYS - TRDSELLS \\
\hline CIRCUIT & CIRCUIT $=1$, if the circuit breakers are imposed during Jan. 1st -7 th, 2015; CIRCUIT $=0$, otherwise \\
\hline POST & $\mathrm{POST}=1$, for the trading days when the circuit breakers are removed; POST $=0$, otherwise \\
\hline GAP5 & GAP5 $=\max (\operatorname{RCSI} 300-(-5 \%), 0)$ if $-5 \%<\operatorname{RCSI} 300 \leq-2 \%$ measures how close in percentage points RCSI 300 is to the $-5 \%$ circuit breaker. \\
\hline GAP7 & GAP7 $=\max (\operatorname{RCSI} 300-(-7 \%), 0)$ if $-7 \%<$ RCSI $300 \leq-4 \%$ measures how close in percentage points RCSI300 is to the $-7 \%$ circuit breaker. \\
\hline VOL.SML & The volume of small-sized trades \\
\hline VOL.MID & The volume of middle-sized or mid-sized trades \\
\hline VOL.LRG & The volume of large-sized trades \\
\hline TRD.SML & The number of small-sized trades \\
\hline TRD.MID & The number of middle-sized or mid-sized trades \\
\hline TRD.LRG & The number of large-sized trades \\
\hline BID & The bid price on the demand schedule \\
\hline ASK & $\begin{array}{l}\text { The ask price on the supply schedule } \\
\text { ASK1. ASK2, and ASK3 are the 1st, 2nd, and 3rd best ask prices, respectively, on the supply schedule. }\end{array}$ \\
\hline SPREAD & $\begin{array}{l}\text { Bid-ask spread, SPREAD = ASK - BID } \\
\text { SPREAD1, SPREAD2, and SPREAD3 are the 1st, 2nd, and 3rd best spreads, respectively, on the demand and supply schedules. }\end{array}$ \\
\hline RSPREAD & The ratio of bid-ask spread to average bid-ask spread; RSPREAD $=\frac{\mathrm{SPREAD}}{(\mathrm{ASK}+\mathrm{BID}) / 2}$ \\
\hline BIDVOL & Bid-volume \\
\hline ASKVOL & $\begin{array}{l}\text { BIDVOL1, BIDVOL2, and BIDVOL3 are the bid-volumes associated with the 1st, 2nd, and 3rd best bids, respectively, on the demand schedule. } \\
\text { Ask-volume } \\
\text { ASKVOL1, ASKVOL2, and ASKVOL3 are the ask-volumes associated the 1st, 2nd, and 3rd best asks, respectively, on the supply schedule. }\end{array}$ \\
\hline QIM & $\begin{array}{l}\text { Quote imbalance, QIM = BIDVOL - ASKVOL, on the demand and supply schedules. } \\
\text { QIM1, QIM2, and QIM } 3 \text { are the quote imbalances associated with the 1st, 2nd, and 3rd best bid and ask quotes, respectively, on the demand and supply schedules. }\end{array}$ \\
\hline
\end{tabular}

